\title{
The evolution of an internal bore at the Malin shelf break
}

\author{
J. Small, T. C. Sawyer and J. C. Scott \\ Defence and Evaluation Research Agency (DERA), Winfrith Technology Centre, Dorset DT2 8XJ, UK E-mail: jsmall@dera.gov.uk
}

Received: 26 March 1998 / Revised: 28 August 1998 / Accepted: 1 October 1998

\begin{abstract}
Observations of internal waves were made at the Malin shelf edge during SESAME (Shelf Edge Studies Acoustic Measurement Experiment), a part of the NERC LOIS-SES experiment, in August-September 1996. These measurements provide a high resolution dataset demonstrating internal wave generation and propagation. This note presents observations of the evolution of an internal bore. The process is shown clearly in a sequence of thermistor chain tows across the shelf break covering a complete tidal cycle, as the double-sided bore transforms into a group of undulations and eventually into more distinct solitary waveforms. Current structures associated with the bore and waves were also observed by ship-mounted ADCP. Analysis of the waveforms in terms of the linear modes and empirical orthogonal functions (EOFs) indicate the dominance of the first mode, which is typical of a shallow water seasonal thermocline environment. Determination of the phase speed of the waves from the consecutive ship surveys enabled the Doppler shift in the towed data to be removed, allowing analysis of the real length scales of the waves. The bore evolution has been modelled using a first order non-linear $\mathrm{KdV}$ model for the first mode, initialised with the waveform in the first survey. Comparison of the model and the observations show close agreement in the amplitudes, length scales, phase speeds and separations of the leading internal waves as they evolve. Finally, analysis of the observed internal wave shapes indicates that, within the uncertainties of measurement, the wave-lengths lie between those predicted by first and second order soliton theory.
\end{abstract}

Key words. Oceanography: general (continental shelf processes; ocean prediction). Oceanography: physical (internal and inertial waves)

\section{Introduction}

Internal bores and high frequency internal waves are a common phenomenon at regions of varying topography such as shelf breaks (Huthnance, 1989; Ostrovsky and Stepanyants, 1989). The generation mechanism is generally accepted to be that of an oscillating tidal flow over these topographic features in a stratified ocean, leading to oscillating vertical velocities which cause displacements of pycnoclines with tidal periodicity. The resulting waves are known as internal tides (Baines, 1982). In some cases the tidal flow over sharp topography will cause a pulse of turbulent current which then collapses in a stratified region giving rise to internal waves (Gargett, 1976; Maxworthy, 1979).

Observations of the internal signal at many shelf breaks (e.g. Bay of Biscay: Pingree et al., 1983; Australian North-West shelf: Holloway et al., 1997) indicate these internal tide period waves are usually accompanied by higher frequency internal waves, typically in the $10 \mathrm{~min}-1 \mathrm{~h}$ period range. These features are commonly seen in remotely sensed data such as high-resolution imaging radar images from Synthetic Aperture Radar (SAR, Alpers 1985; Gasparovic et al., 1988), in packets separated by the wavelength of the internal tide, and they have been observed to obtain large amplitudes (e.g. up to $50 \mathrm{~m}$, New and Pingree, 1990).

Recently, much research has been done into how the internal tides evolve into the higher frequency internal waves under the influence of non-linear effects, dispersion, shoaling and friction (e.g. Holloway et al., 1997, Lamb 1994). The classic explanation was detailed by Zabusky and Kruskal (1965), in terms of the theory of non-linear waves formulated by Korteweg and de-Vries (KdV: 1895): initially non-linear effects steepen the wave to form an internal hydraulic bore, then non-hydrostatic dispersive effects act to form wave-like instabilities behind the bore which grow, separate, and eventually form a sequence of solitary waves. 
Current research into high frequency internal waves includes analysis using more non-linear, extended $\mathrm{KdV}$ type equations (Lamb and Yan, 1996), and investigation of the role of energy supply and dissipation (Henyey and Hoering, 1997). The theory has been applied to the shelf break regions mentioned and to other areas such as the Strait of Gibraltar (Brandt et al., 1996).

This work describes observations of the evolution of an internal bore at the Malin shelf-break during the Shelf Edge Studies Acoustic Measurement Experiment (SESAME), and its modelling using $\mathrm{KdV}$ theory. SESAME was a DERA led international experiment in collaboration with the Naval Research Laboratory (NRL, Bay St Louis, USA), and also involving ships from the French and Netherlands Defence research community. SESAME contributed combined acoustic/ hydrographic measurement moorings, and towed surveys with ADCP and thermistor chain.

SESAME was run alongside the Shelf Edge Study (SES), a major NERC sponsored survey investigating shelf edge processes and shelf-ocean interactions. The experiment took place at the Malin shelf/ocean margin, on the UK Continental Shelf, west of Scotland (Fig. 1). The shelf here is typically $140 \mathrm{~m}$ deep, whilst the slope extends down to the $2500 \mathrm{~m}$ deep Rockall Trough to the west. The area also includes the Hebrides Terrace seamount which rises to $\sim 980 \mathrm{~m}$.

The data described is from SESAME II, August 1996, and consists of repeated tows across the shelf break. The data shows clearly the evolution of an internal bore into a set of high frequency waves, allowing analysis of the evolution of the waves.

\section{Observations}

A sequence of tows across the Malin shelf break along a parallel of latitude at $56^{\circ} 30^{\prime} \mathrm{N}$ were made between the 12 and 14 August, 1996, covering four M2 tidal cycles. This section discusses the observations on 13 August of an evolving internal bore.

\subsection{Measurement systems}

This experiment obtained generally good data from hullmounted ADCP and towed thermistor chain. Towing speeds were typically 4 knots $\left(2.2 \mathrm{~m} \mathrm{~s}^{-1}\right)$. In the later sections the tow data is converted to approximate synoptic data by removing the Doppler shift due to the phase speed of the internal waves. The largest sources of error in this method will be due to the assumption of a constant wave phase speed, and a fixed west-east propagation direction. As discussed already the speed of non-linear waves is dependent on the wave amplitude, and changes as they evolve. However, as the phase speed $\left(0.3 \mathrm{~m} \mathrm{~s}^{-1}\right)$ is small compared to the tow speed, fractional changes in phase speed are likely to make little difference in the derived synoptic plots. This is discussed further later.

The thermistor chain data is sub-sampled from an original frequency of $1 \mathrm{~Hz}$ to once every $20 \mathrm{~s}$, a frequency which was more manageable for analysis and still resolved the internal waves. The thermistor chain had 8 thermistors which recorded at depth intervals of approximately $10 \mathrm{~m}$, with the minimum depth being $5 \mathrm{~m}$.

The ADCP averaged over 2 min periods, a sixth of the resolution of the thermistor chain plots. The vertical resolution of the ADCP was $8 \mathrm{~m}$ with top level $17.5 \mathrm{~m}$ below the surface. Error values occurred in the bottom $20 \mathrm{~m}$ in the shelf depth of $140-150 \mathrm{~m}$, and these depths were not considered in the analysis.

\subsection{Temperature structure}

Figure 2 shows isothermal contours of the thermistor chain data, aligned so that each plot covers the same

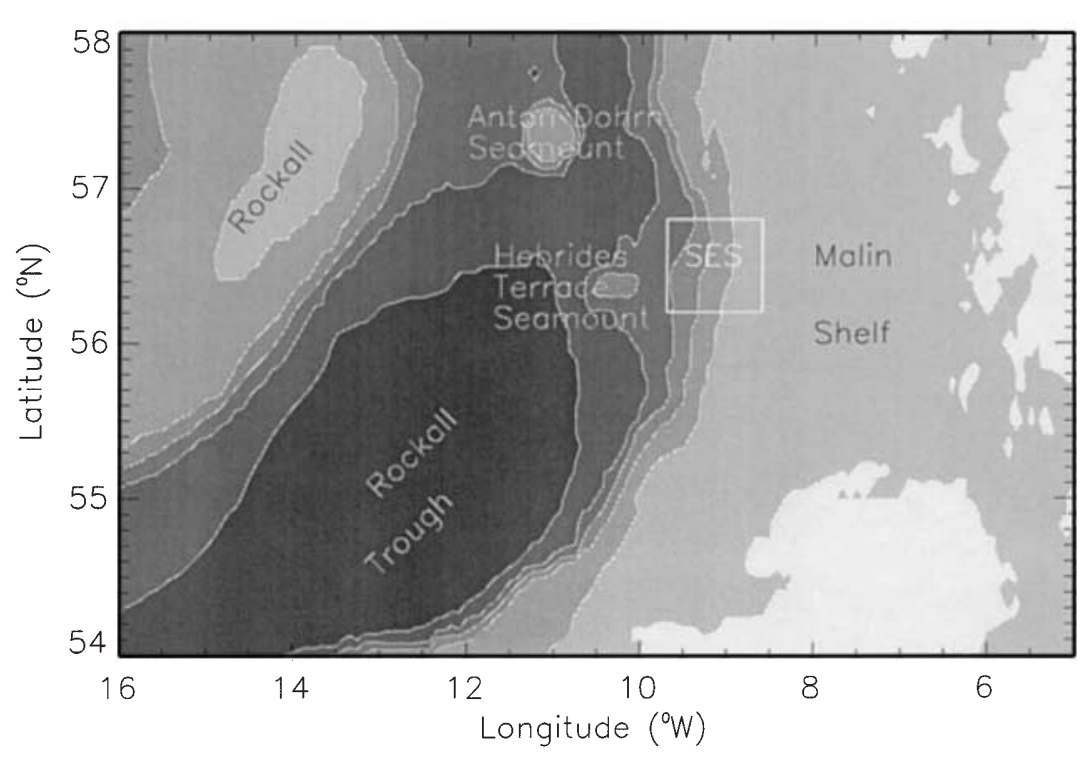

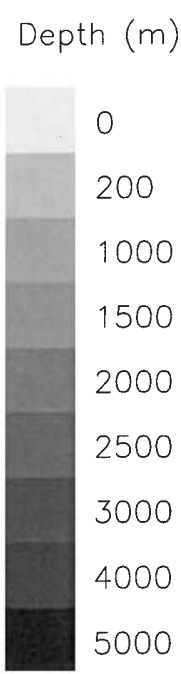

Fig. 1. Bathymetry of the UK Continental Shelf and slope, taken from the ETOP 05 database. Depth in metres 


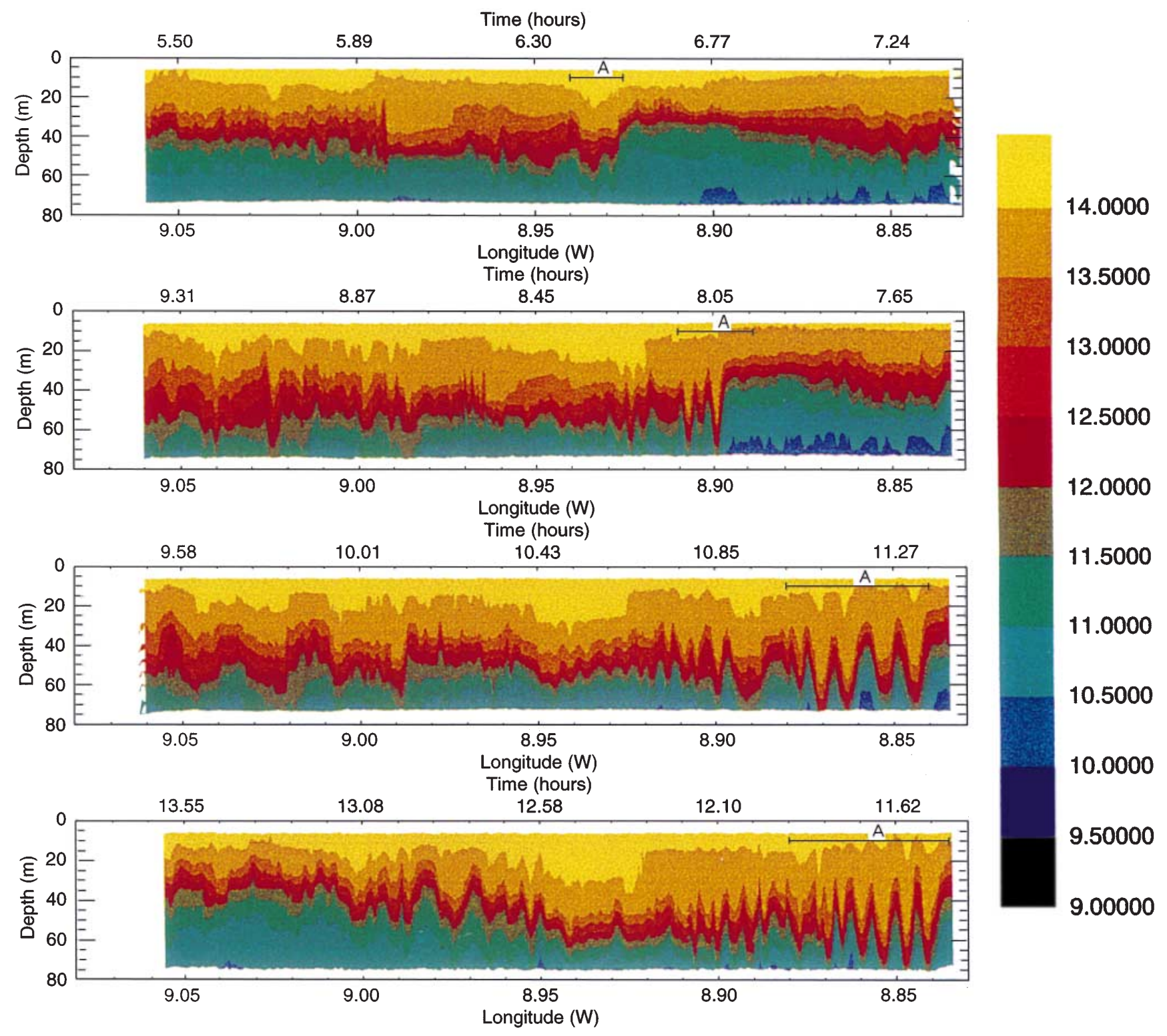

Fig. 2. Contours of temperature in ${ }^{\circ} \mathrm{C}$ from the thermistor chain for four consecutive surveys across the Malin shelf-edge. Longitude position is marked at the bottom of each plot, time at the top

longitude range, for four tracks of the survey sequence. Longitude is shown at the bottom of each individual plot, and time at the top. The figure indicates large variations in the depth of the seasonal thermocline, and the sections are notable for showing a significant amount of high frequency internal wave activity, together with an overlying, low frequency oscillation in thermocline depth due to the internal tide. Throughout this study, the surveys shown here will be referred to as surveys 1, 2, 3, and 4 respectively, ordered in increasing time.

We have concentrated on the evolution of a particular feature seen in these plots, marked 'A' in Fig. 2. The propagation of the feature was initially identified visually in these plots, by following the propagation of the underlying trend of the thermocline depth, noting that high frequency features would continuously be generating and evolving. This identification was con- firmed by comparing the phase speed of the leading (right-hand) edge of the feature, (obtained by removing tidal advection from the observed speed across the ground, using the barotropic tide model discussed in Sect. 2.3) between the four sections, and finding comparable phase speeds of around $30 \mathrm{~cm} \mathrm{~s}^{-1}$ between each plot (see Table 1). (Here an assumption is made that the waves are travelling due east, perpendicular to the shelf edge: this is justified further in Sect. 2.6 and 5)

In Table 1 it can be seen that the phase speed is greater in the second measurement than in the first, and this may be explained by the non-linear wave characteristic of increasing phase speed as the wave evolves and grows. The third measurement is only approximate, as the distances used to derive phase speed $(\mathrm{O}(100 \mathrm{~m}))$ were of the order of the GPS error. The speed averaged over the first to last measurement is $32 \mathrm{~cm} \mathrm{~s}^{-1}$. 
Table 1. Speed across ground and phase speeds between the surveys (west-east component)

\begin{tabular}{lclc}
\hline Survey & $\begin{array}{l}\text { Speed over } \\
\text { ground }\left(\mathrm{cm} \mathrm{s}^{-1}\right)\end{array}$ & $\begin{array}{l}\text { Time-average tidal } \\
\text { speed along track } \\
\left(\mathrm{cm} \mathrm{s}^{-1}\right)\end{array}$ & $\begin{array}{l}\text { Wave phase } \\
\text { speed }\left(\mathrm{cm} \mathrm{s}^{-1}\right)\end{array}$ \\
\hline $1-2$ & 31 & 5 & 26 \\
$2-3$ & 28 & -7 & 35 \\
$3-4$ & 24 & -4 & 28 \\
Total & 29 & -3 & 32 \\
$1-4$ & & & \\
\hline
\end{tabular}

The longitude-time plot for the four surveys is shown in Fig. 3a. Position data was acquired from a GPS system. (The $\sim 100 \mathrm{~m}$ accuracy of GPS was sufficient for most of the calculations used in this study: but it does place some uncertainty on the measurements of small length scales such as internal wave widths). Also shown are the positions of intersection of the leading (eastward) edge of the feature 'A'. Figure $3 b$ shows detailed swath bathymetry from the SES experiment (McCartney and Huthnance, 1995), with the track shown. It can be seen that the survey mainly covered shelf depths of less than $160 \mathrm{~m}$ (typical values of $140 \mathrm{~m}$ ), and briefly crossed the shelf break down to just over $300 \mathrm{~m}$ at the western end of the survey track. The data considered was all gathered over the shelf.
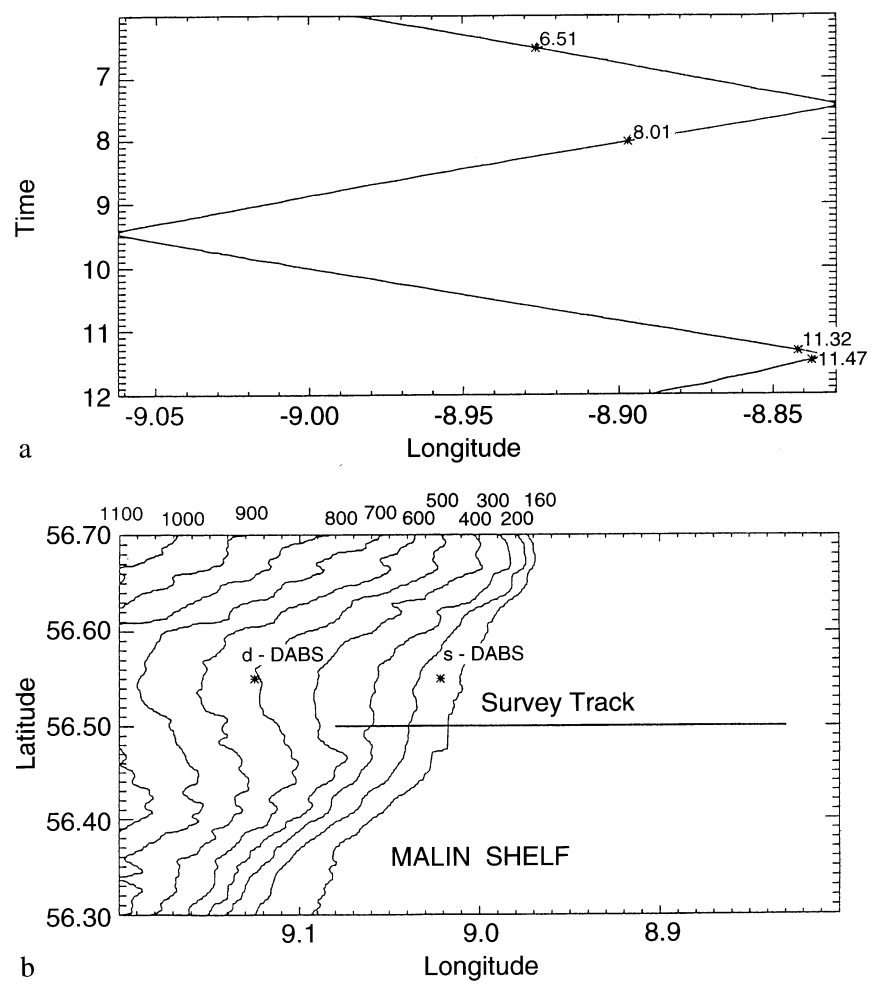

Fig. 3. a Longitude-time track plot, with the points of intersection of the front of the feature ' $A$ ' (Fig. 2) marked. The onshelf propagation can be seen at a fairly constant rate, dependent on wave phase speed and tidal advection. b Detailed bathymetry of the survey region, taken from the SES dataset, with the position of the survey track marked. Also shown are the positions of the moorings studied in Small et al. (1998) Bathymetry contour levels (m) shown at top.
Figure 4 shows a close up of part of the temperature structure through the feature ' $A$ ', as a function of time, with each plot aligned with the leading edge of the feature at the right hand edge. (The time limits of each of these plots were chosen so that, after adjustment for Doppler shifting (see later), the plots all covered about $4000 \mathrm{~m}$, a range that seemed to include the whole feature after it had evolved.) The cross sections show the feature evolving from a square 'well'-shaped depressional bore in the first survey, through an undular bore with three well-defined waves in the second survey, into a more developed wave packet of four distinct waves, followed by smaller waves, in the last two surveys. (The internal wave packet shown in the last two surveys was surveyed in opposite directions in quick succession and hence has not evolved significantly.)

In order to conduct the modelling experiments described in Sect. 4, snapshots of the internal wave field were required. Of course ship tows do not give snapshots, as the internal waves are propagating, and a simple relativity approach was applied to remove the Doppler shift effect. Here an approximation was made for the speed across the ground (taken to be equal to phase speed plus the eastward component of barotropic tide velocity) by assuming the whole field had the speed of the bore feature. (This is a rough approximation, but it was checked successfully by comparison of the calculated width of the waves in surveys 3 and 4 . As the waves had not evolved much between these two survey tracks, it would be expected that they would have similar widths, as was calculated, and shown in Sect. 4.4.)

Using the simple relativity method, and assuming the waveform is moving at a fixed speed $\mathrm{C}$ west-east, snapshots of the temperature field $T_{i}\left(x, z, t=t_{0}\right)$, where $i$ is the survey number, can be derived from

$$
\begin{aligned}
& T_{i}\left(x, z, t=t_{0}\right)=T(r, z, t) \\
& \text { where } \quad x=r \pm C\left(t-t_{0}\right)
\end{aligned}
$$

where $r$ is the tow distance, $x$ is the range (with Doppler shift removed) at $t=t_{0}, t$ is the tow time, $T(r$, $z, t)$ is the recorded temperature during the tow, and \pm corresponds to the ship speed being in the opposite/ same direction as the wave speed respectively. (The plots in Fig. 2 indicate clearly that the waves were propagating onshelf.) This method assumes that the waveform does not evolve significantly during the period of towing through one survey, and it results in snapshots centred around $6.3 \mathrm{~h}, 8.3 \mathrm{~h}, 11.2 \mathrm{~h}$ and $11.6 \mathrm{~h}$. The speed across ground of the internal tide was assumed to be $30 \mathrm{~cm} \mathrm{~s}^{-1}$ for all surveys, consistent with Table 1.

The resulting snapshots are shown in Fig. 5 for $4 \mathrm{~km}$ long cross-sections including the bore feature. The feature is seen to evolve from a $\sim 600 \mathrm{~m}$ width 'well' in the first survey through to a series of four internal waves of depression covering a $2000 \mathrm{~m}$ range about $5 \mathrm{~h}$ later. These are shown at a similar stage of development in the last two plots. The initial bore has a peak to trough amplitude of $28 \mathrm{~m}$ (for the $11.5^{\circ} \mathrm{C}$ isotherm, chosen for 

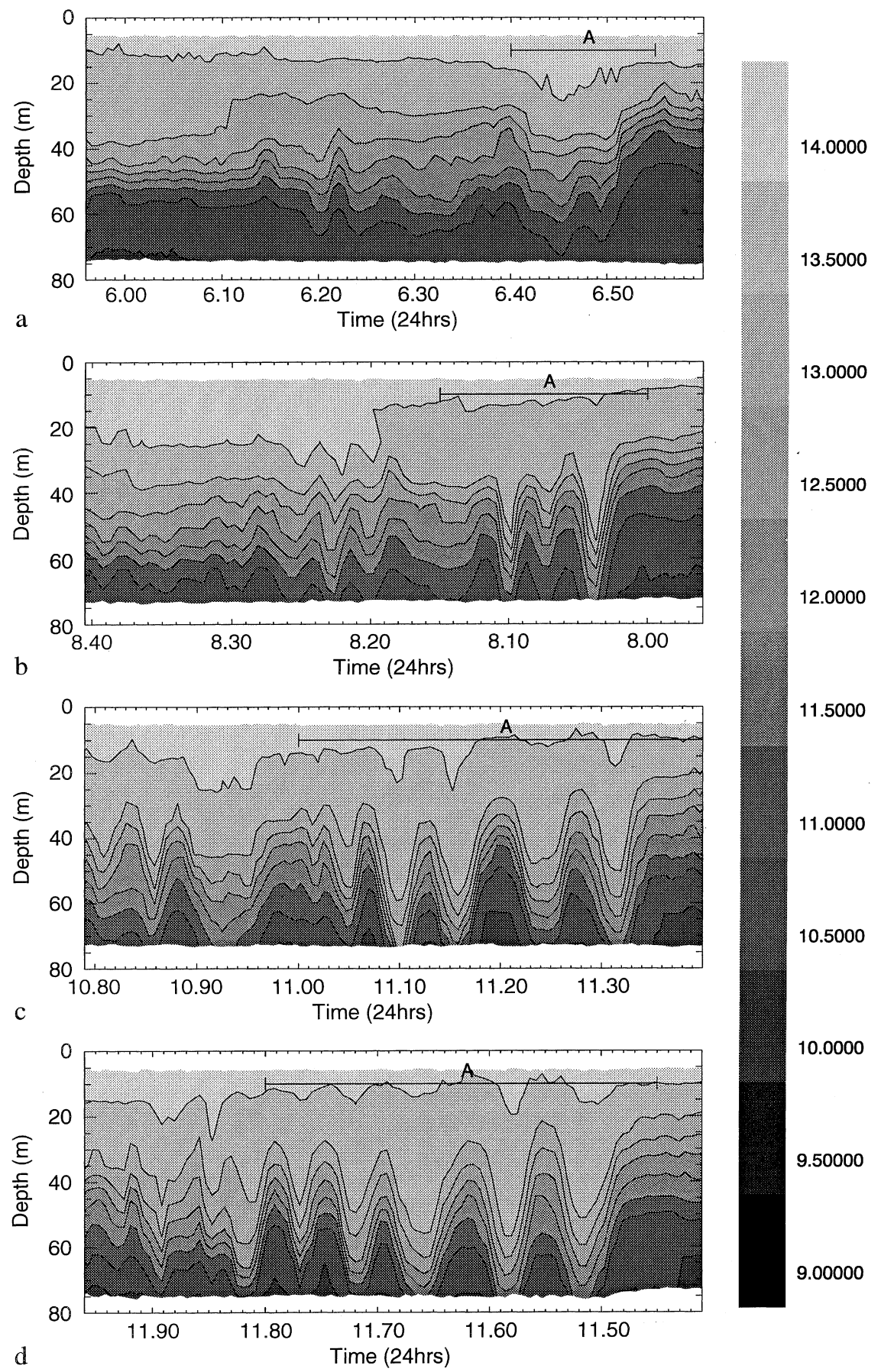

Fig. 4a-d. Close up temperature $\left({ }^{\circ} \mathrm{C}\right)$ cros-sections across the feature ' $A$ ' in the four surveys, as a function of time, but with the second and fourth survey reversed to show similar orientations of the wave packet for all four surveys

reasons discussed later). After $1.5 \mathrm{~h}$ three waves have evolved spanning a total of about $900 \mathrm{~m}$, the leading wave having an amplitude of some $35 \mathrm{~m}$. After $5 \mathrm{~h}$ of evolution the leading four waves have $25-35 \mathrm{~m}$ peak-trough amplitudes and are separated by about $500 \mathrm{~m}$, spanning over $2 \mathrm{~km}$. Behind the four main internal waves, oscillations of smaller amplitude and wavelength occur.

\subsection{Barotropic tide}

The barotropic tide was derived from a depth average of the ADCP current vectors to $80 \%$ of the total depth (beyond this level instrument errors could occur). As the ADCP was being towed over varying topography, the original signal contained variations in tidal amplitude due to the different depths. This effect was corrected by assuming that the tidal flux $H U$, where $H$ is the water depth and $U$ the cross-slope tidal velocity, is constant, and then calculating the tidal velocity at a fixed depth of $140 \mathrm{~m}$, the common shelf depth.

The orientation of the shelf break at the latitude $56^{\circ}$ $30^{\prime}$ is between $000{ }^{\circ} \mathrm{T}$ - and $010^{\circ} \mathrm{T}$ and so the $U$ velocity is approximately across-slope. The depth averaged $U$ and $V$ (south-north) velocities for depth $140 \mathrm{~m}$ are 


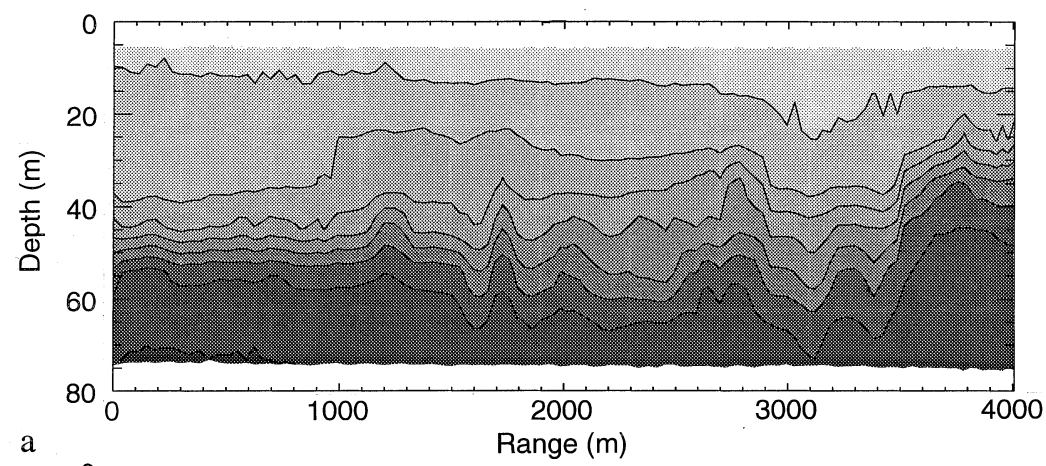

14.0000

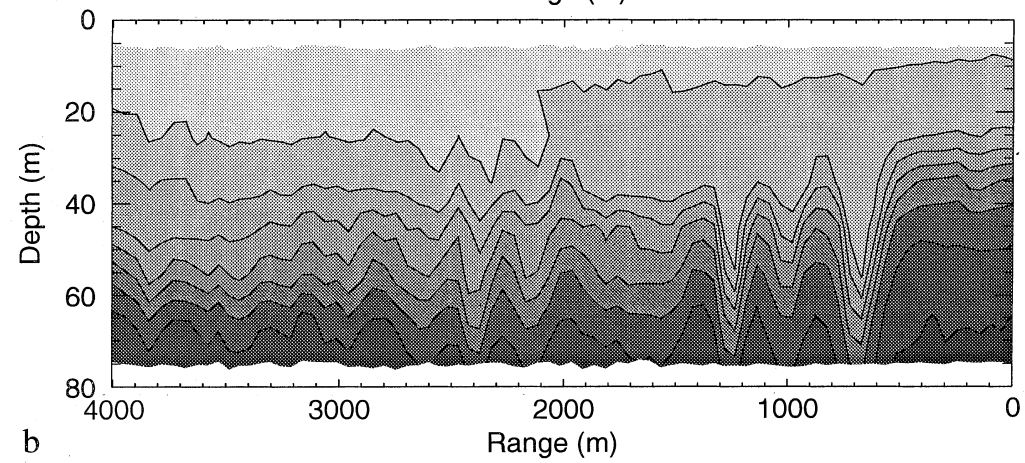

b Range $(m)$
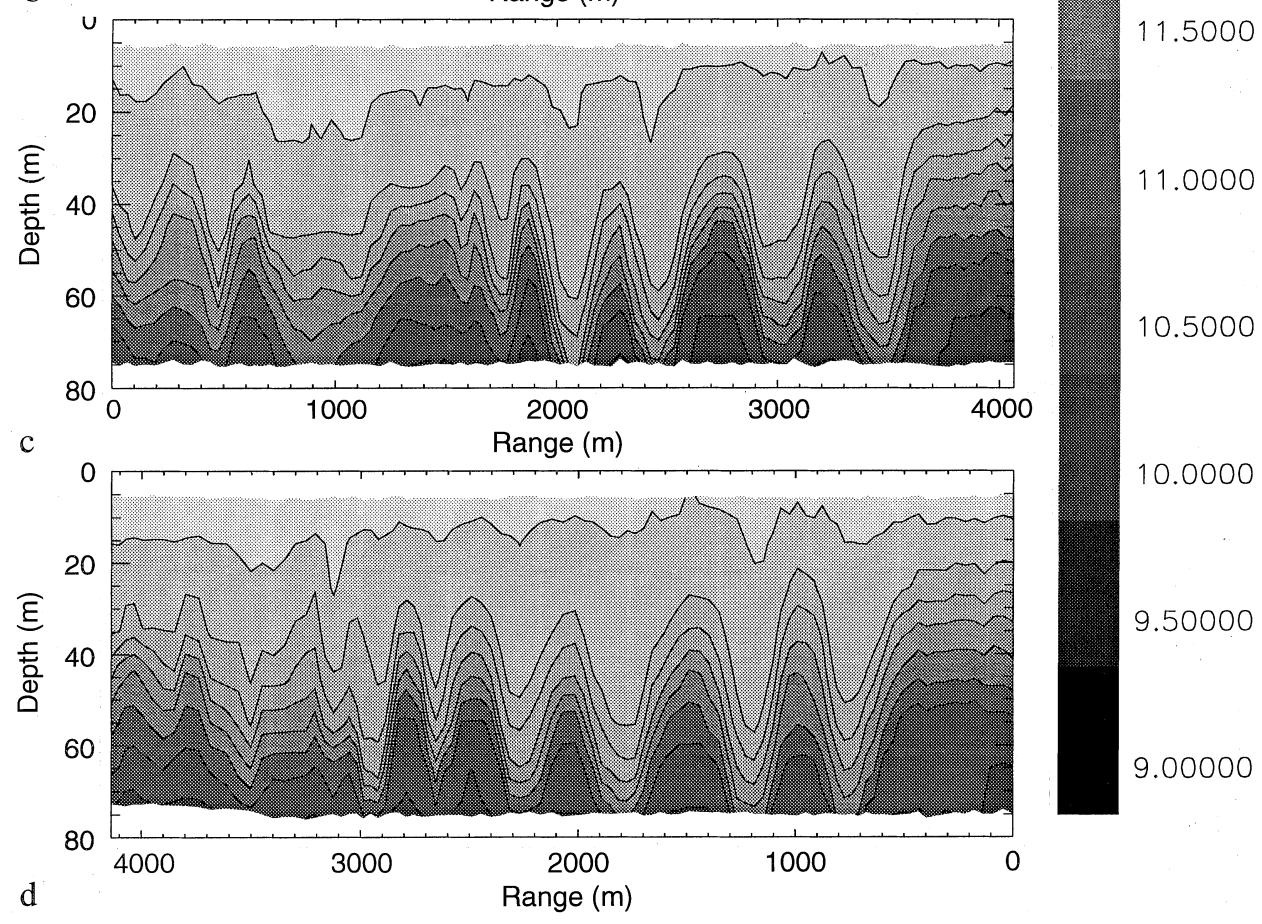

13.0000

12.5000

12.0000

11.5000

11.0000

10.5000

Fig. 5a-d. 'Snapshots' of the feature ' $A$ ' derived from Fig. 4 by assuming a constant wave speed across ground of $0.3 \mathrm{~m} / \mathrm{s}$, and removing the Doppler shift. Cross sections of four kilometre lengths are shown for consistency. Once again all plots are aligned to show the feature at the right. Temperature in ${ }^{\circ} \mathrm{C}$

shown in Fig. 6 for the $12 \mathrm{~h}$ period $0200-1400$ of the 13 August, smoothed over a $1 \mathrm{~h}$ running average.

The tidal velocity derived from the ADCP data was compared against a tidal prediction made by harmonic decomposition of data from a moored ADCP deployed during the coincident 1995 SES survey (this model is described in full in Small et al. (1998)) and the results are overplotted on the 13 August data. The agreement between the two is generally good to within $5 \mathrm{~cm} \mathrm{~s}^{-1}$ and gives confidence in the tidal curve shown (the differences notable between 5-6 h, 9-10 $\mathrm{h}$ and 13-14 h were obtained when the ship was off-shelf and the ADCP did not measure to full depth, inducing a bias to the barotropic estimate. For this reason the harmonic model is used in the tidal calculations here).

Figure 6 also shows the tidal current ellipse for the whole $24 \mathrm{~h}$ of the 13 August, with the position every $2 \mathrm{~h}$ marked, computed from the tidal predictor. The tidal velocity during the time of the bore observations was weakening, ranging between $+/-10 \mathrm{~cm} \mathrm{~s}^{-1}$, and veering from eastwards to south/southwestwards.

The tidal signal from the harmonic model was used to remove tidal advection from the wave speed across ground to obtain phase speeds for the evolving bore, as shown in Table 1. It was also used to derive the internal baroclinic velocities discussed later. 

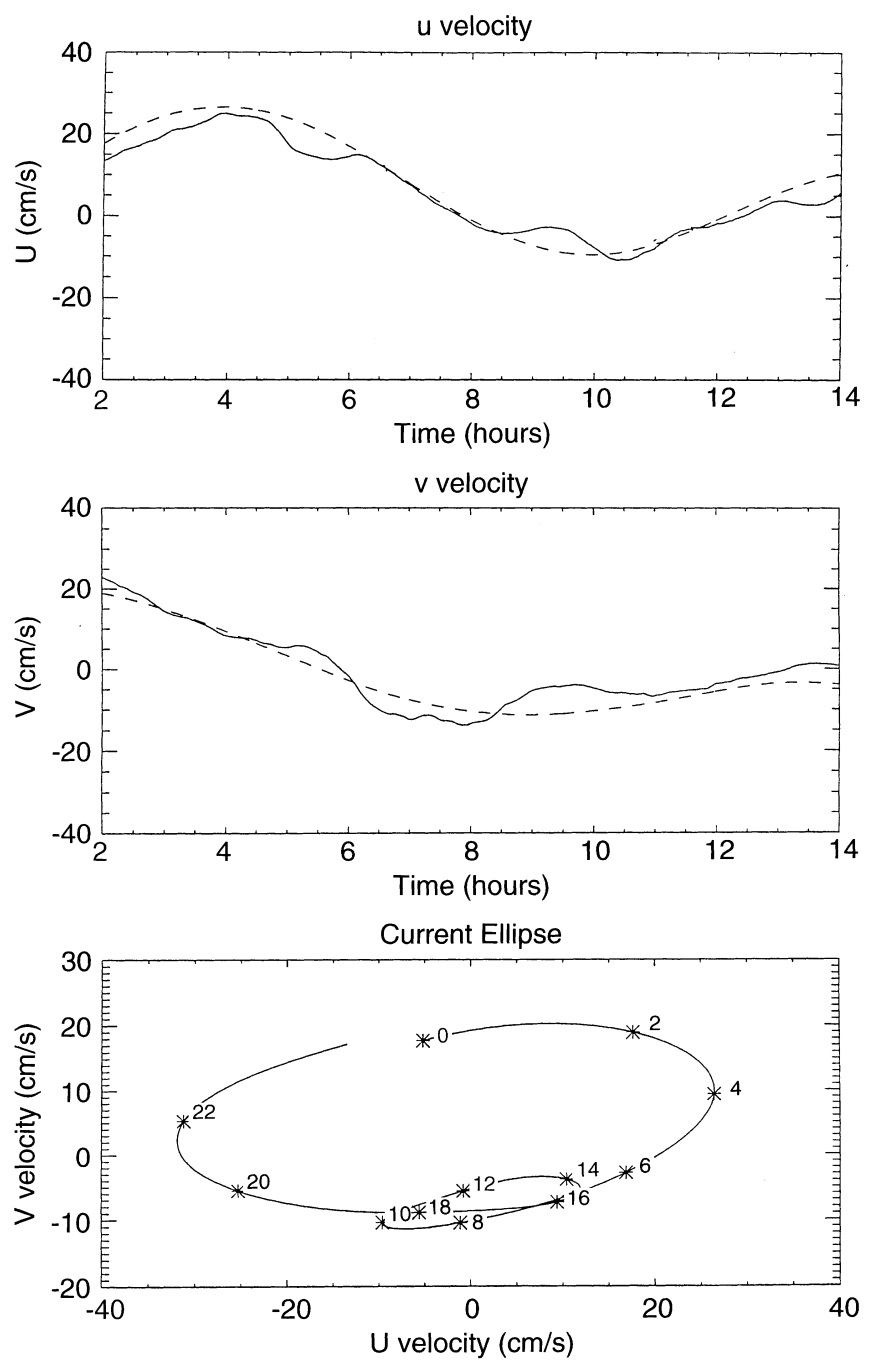

Fig. 6a-c. Barotropic tides on the 13th August 1996 in the survey region. a smoothed, depth averaged $u$ velocity from ADCP in $\mathrm{cm} / \mathrm{s}$, and $\mathbf{b}$ corresponding $v$ velocity in $\mathrm{cm} / \mathrm{s}$. The smoothing was done over $1 \mathrm{~h}$. Overplotted as a dashed line is the prediction from the model of Small et al. (1998). c Tidal ellipse from the model for 13th August, with 2 hourly positions marked

\subsection{Currents}

Figure 7 shows raw currents from the ADCP for the corresponding surveys to the thermistor chain plots described already. Once again the Doppler shift has been removed to give a range plot over $\sim 4000 \mathrm{~m}$. Overplotted is the position of the $12{ }^{\circ} \mathrm{C}$ contour (typical thermocline isotherm) from the corresponding thermistor chain data, but sub-sampled to the coarser ADCP resolution.

The first two surveys indicate strong offshelf (negative) pulses of near surface water on the right hand (shelf) side of the bore. In the first survey this flow opposes the onshelf tide, and has speeds of $15-20 \mathrm{~cm} \mathrm{~s}^{-1}$, increasing to $25-30 \mathrm{~cm} \mathrm{~s}^{-1}$ in the second survey as the tide becomes slack (in the cross-slope sense: see Fig. 6 at $0800 \mathrm{~h}$ ). The temperature of the pulse is above $13{ }^{\circ} \mathrm{C}$ and is in the top 20-30 m layer (unfortunately no ADCP data was available in the top $17.5 \mathrm{~m}$ ).
In the final two surveys the flow is almost two-layered and similar to the baroclinic velocities (discussed later), as the onshelf tide is almost slack in this period. The upper layer has onshelf flow and the lower layer is offshelf, consistent with a trough in the overall internal tidal wave. Unfortunately the individual internal waves are not well resolved by the ADCP (compare the subsampled $12{ }^{\circ} \mathrm{C}$ depth with Fig. 5 which shows the same surveys), as the data was averaged over a 2 min period which, in some cases spans the peak-trough distance of an internal wave, but some pulses associated with the waves can be seen.

\subsection{Internal currents}

In contrast to the barotropic tide, the internal tide at a shelf edge has short wavelengths (typically $10-30 \mathrm{~km}$ ) when compared to towing distance, and hence the towed data cannot be used to obtain the whole structure of the internal tide phase and amplitude across the surveyed region. However, an idea can be got of the instantaneous internal tide at the times of interest here.

Figure 8 shows the internal $\mathrm{u}$ currents (original $u$ velocity minus the tidal $U$ velocity). As mentioned already, the bore in survey 1 is characterised by strong offshelf flow in the upper layer. Some evidence of higher modes (more than one zero crossing of velocity) is evident to the left hand side of the bore in the first two surveys. (This was confirmed in plots of the displacement, not shown.) The internal waves in the last two surveys are shown to have opposing direction velocities in the upper and lower layer, as expected from 2 layer or first mode theory, with onshelf currents in the top layer and offshelf in the lower layer. The poor sampling of the ADCP meant that the individual internal wave currents are not well resolved.

One point of interest of relevance to the following modelling (Sect. 4) is the depth of zero crossing in the 2 layer situations of the bore in the first two surveys, and the internal waves in the last two surveys. From the plots, a depth of 45-55 $\mathrm{m}$ can be discerned for the bore, whereas deeper values of 60-70 $\mathrm{m}$ occur in the internal waves. This is possibly a result of the strongly non-linear effects present here.

\subsection{Propagation direction of the internal tide}

In Sect. 2.2 the phase speed of the internal waves were calculated under the assumption that the waves were travelling in the same direction as the survey track, i.e. due east, perpendicular to the shelf break. On this occasion, there were no surface signatures available from ship-radar or SAR to validate this (until 8 days later, see Discussion). There remains the possibility of deriving propagation direction from the internal currents within the waves. As discussed, the ADCP poorly sampled (and averaged) the high frequency internal waves that evolved in the last three surveys. However, an idea of the wave directions can be gleaned from the better-sampled internal bore in the first survey. 

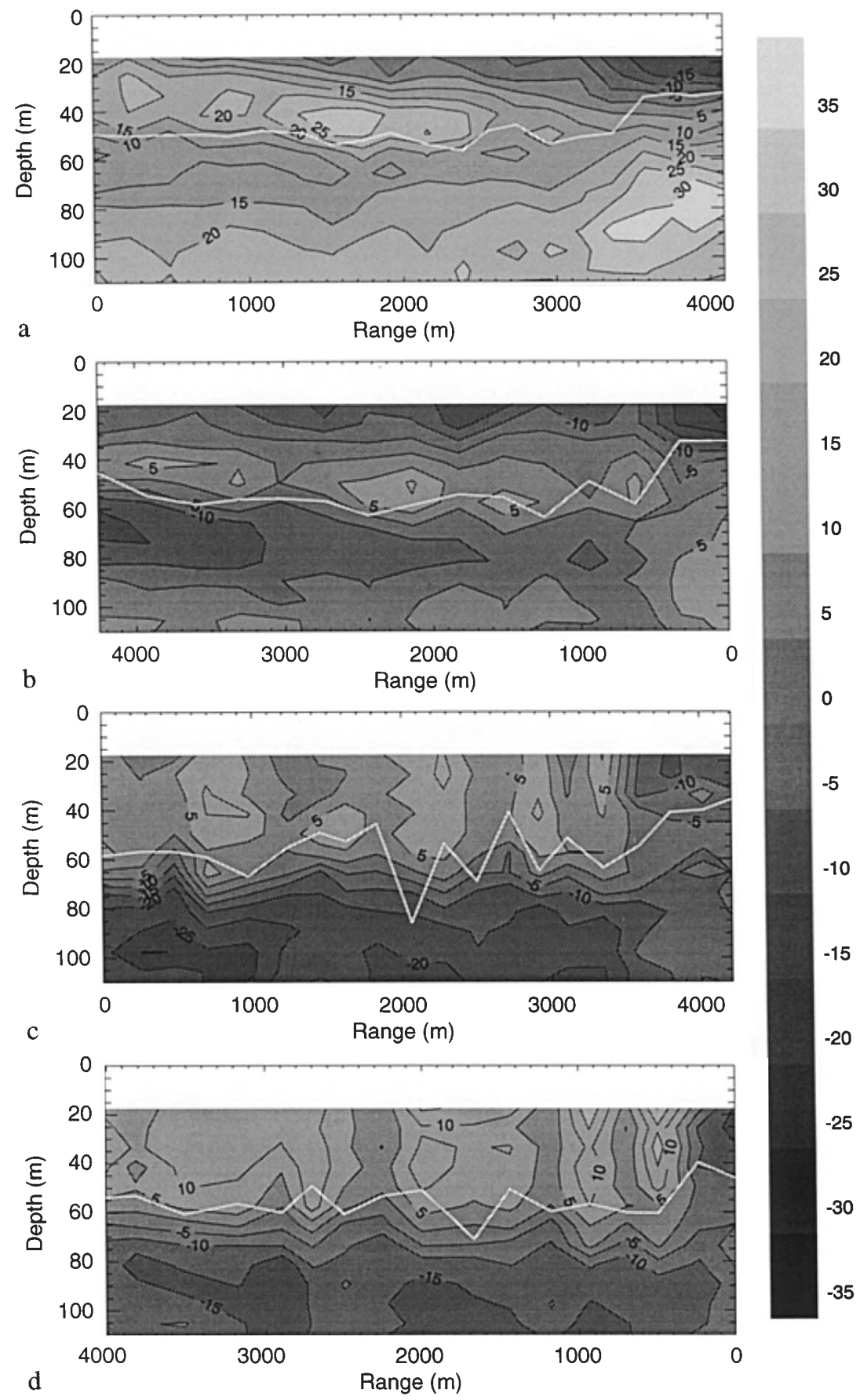

Fig. 7a-d. Raw eastward currents from ADCP for the four surveys of Fig. 5, shown as a function of range. Overplotted is the $12{ }^{\circ} \mathrm{C}$ isotherm from the thermistor chain data sub-sampled to the ADCP resolution. Velocities in $\mathrm{cm} \mathrm{s}^{-1}$

Figure 8 showed a strong baroclinic $u$ velocity associated with the right hand (elevated) part of the bore. Figure 9 shows the magnitude and directions of the internal currents at the levels of current maxima in Fig. 8a, in the upper (Fig. 9a, b) and lower (Fig. 9c, d) layers. The occurrence of the baroclinic surge can be seen onsetting around $6.5 \mathrm{~h}$ in the plots. Overplotted on the direction plots are the $270{ }^{\circ} \mathrm{T}$ (offshelf) direction (Fig. 9b) and the on-shelf $\left(90^{\circ} \mathrm{T}\right)$ direction (Fig. 9d). The currents in the upper and lower layers rotate around anticlockwise towards these directions in the elevated part of the bore.

For a first mode internal wave, the currents in the upper layer above a wave crest should oppose the propagation direction, and lower layer currents should follow the direction. It follows that the internal bore appears to be propagating almost due east (to within $10^{\circ}$ ). In this study this assumption of eastward propagation will be made for the internal wave field in all four surveys. The point is discussed further, in relation to a SAR image of the region taken on a different day, in Sect. 5.

\subsection{Mean stratification during August 1996}

A measure of the stratification which governs internal wave dynamics is the buoyancy frequency $N$, given by 

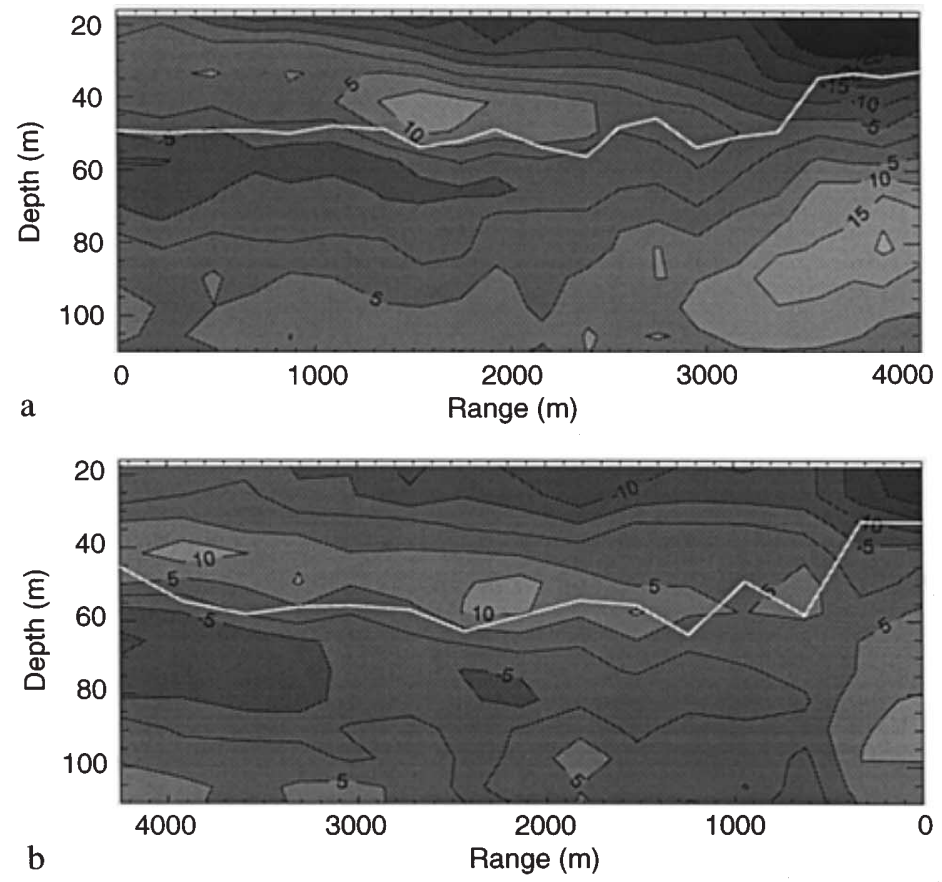

20
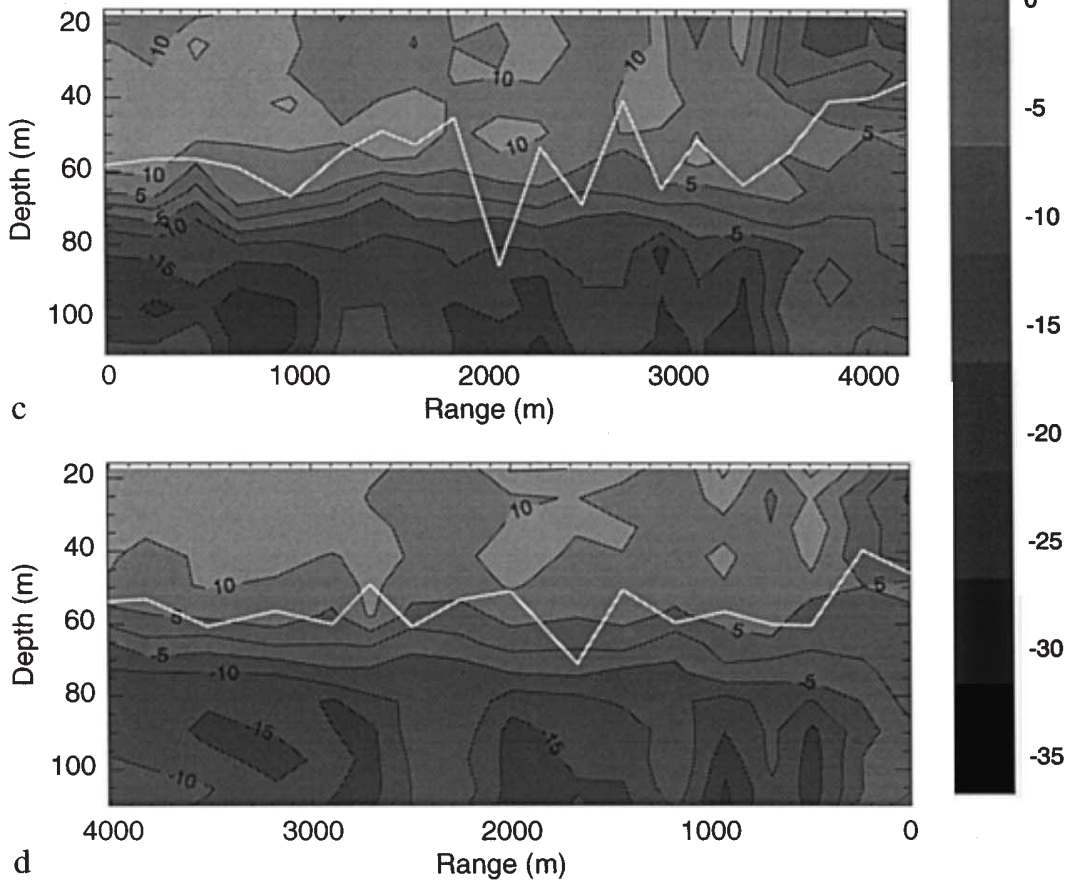

Fig. 8a-d. Internal eastward currents from ADCP for the four surveys of Fig. 5, shown as a function of range. Here the depth averaged ADCP values have been removed from the original signal. Overplotted is the $12{ }^{\circ} \mathrm{C}$ isotherm from the thermistor chain data sub-sampled to the ADCP resolution. Velocities in $\mathrm{cm} \mathrm{s}^{-1}$

$N^{2}=-\frac{g}{\rho_{0}} \frac{\partial \rho}{\partial z}$

The buoyancy frequency was derived using mean profiles for the period of observation. The mean temperature $(T)$ was derived from regular XBT drops (every half hour) during the deployment of the thermistor chain and ADCP between 12-14 August. To compensate for the lack of salinity data, salinity was derived from the temperature using a mean temperaturesalinity $(T S)$ relationship of 230 CTDs taken during the SES 1995 experiment. (In fact, calculations with different possible salinity ranges gave similar density profiles to within $0.05 \mathrm{~kg} \mathrm{~m}^{-3}$, and buoyancy frequencies to within $1 \mathrm{cph}$ in the pycnocline, confirming that temperature had the dominant effect on the stratification in this environment.) The potential density was then derived from the UNESCO (1983) equation of state, and buoyancy frequency calculated using a centred difference version of Eq. (2).

Figure 10 shows the $T, S$, density and buoyancy frequency thus obtained. (Values at depths above $10 \mathrm{~m}$ were not plotted as the XBT data was unreliable there.) The seasonal thermocline is strong and centred around $40 \mathrm{~m}$ depth, as seen in the buoyancy frequency which peaks there at around $8 \mathrm{cph}$. 

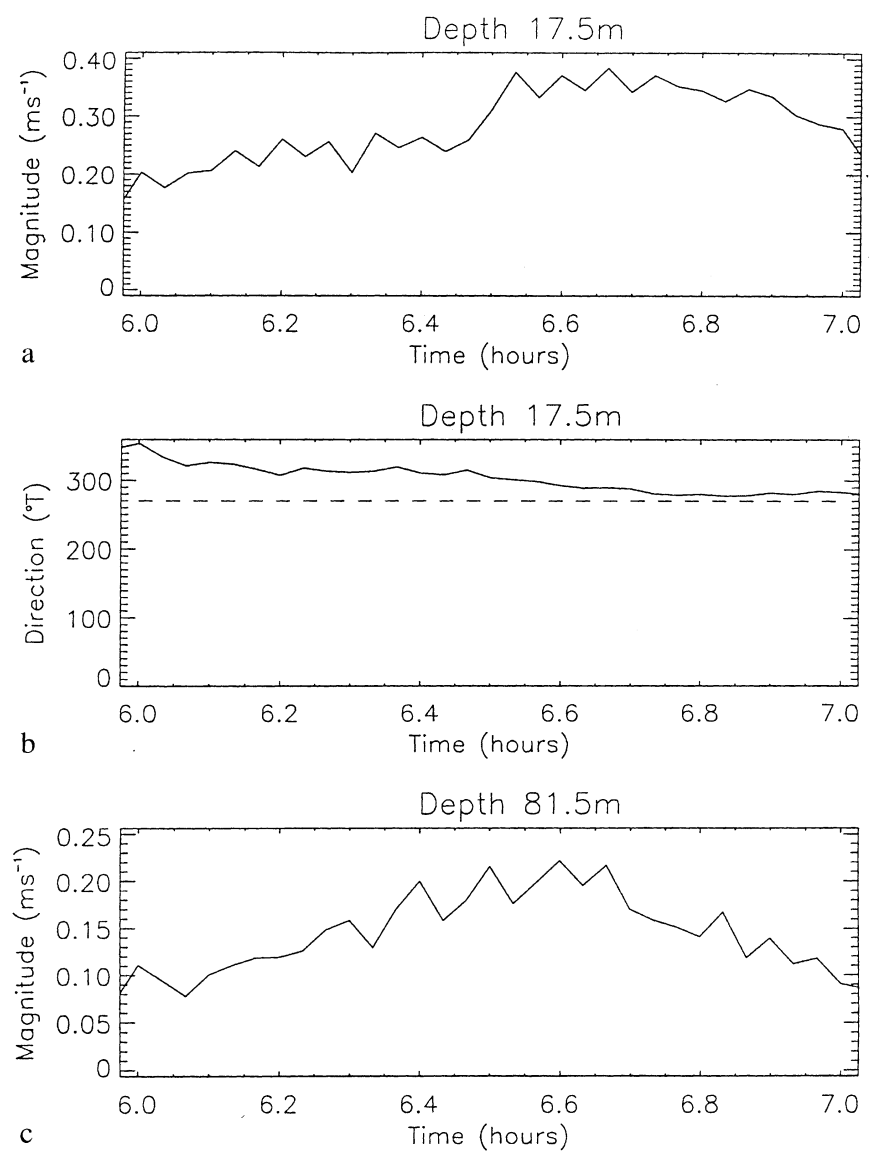

c

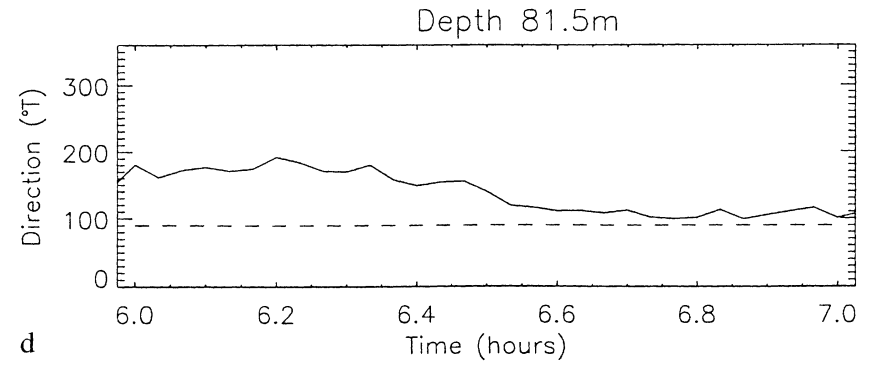

Fig. 9a-d. Magnitude and direction of the internal currents at a, b $17.5 \mathrm{~m}$ depth and $\mathbf{c}, \mathbf{d} 81.5 \mathrm{~m}$ depth from ADCP, between 0600 and 0700 h, 13 August, 1996. Overplotted on the direction plots is the b $270{ }^{\circ} \mathrm{T}$ and $\mathbf{d} 090^{\circ} \mathrm{T}$ angles indicating the cross-slope (and survey track) direction

\section{Deductions from linear internal wave theory}

\subsection{Linear modes of oscillation}

The initial stages of the formation of the internal tide may be described by linear theory if the amplitude is small enough. As the internal tide grows and shoals in shallower water the amplitude may then be large enough for non-linear effects to be important. These effects are discussed in Sect. 4. Here the linear modes are discussed and applied to the early stage of the bore.

The modes of oscillation of displacement are solutions to the linearised equations of motion for a Boussinesq fluid in two dimensions and with no current shear, given by $\frac{\partial^{2} \phi_{i}(z)}{\partial z^{2}}+k_{i}^{2} \frac{N^{2}-\omega^{2}}{\left(\omega^{2}-f^{2}\right)} \phi_{i}(z)=0$

$\phi_{i}=0 \quad$ at $z=0,-h$

where the $\left\{\phi_{i}: I=1, n\right\}$ are displacement eigenvectors of Eq. 3 with corresponding eigenvalues $k_{i}, N$ is the buoyancy frequency, $f$ is the inertial frequency $z$ is the height from the sea surface and $h$ is the water depth. Then the $\phi_{I}(z)$ are the normal modes and $k_{i}$ the wave numbers of the linear waves.

For our example the seabed varied between $140 \mathrm{~m}$ and $150 \mathrm{~m}$, and the buoyancy frequency used was that shown in Sect. 2.7. A number of possible internal wave frequencies were tried to simulate the observed phase speed $c_{i}\left(c_{i}=\omega / k_{i}\right)$ of the internal bore. The best fit was given for a first mode wave period of $15 \mathrm{~min}$ : in fact this ties in nicely with the observed time scales of the bore and internal waves. (It was found that as the linear internal wave period approached the maximum buoyancy frequency $(8 \mathrm{cph})$, the theoretical phase speed reduced from $\sim 40 \mathrm{~cm} \mathrm{~s}^{-1}$ at $1 \mathrm{~h}$ period to $29 \mathrm{~cm} \mathrm{~s}^{-1}$ for the 15 min period.)

The linear modes were derived from Eq. (3) with the buoyancy frequency of Fig. 10 using a shooting technique (courtesy of Dr Toby Sherwin), Fig. 11 shows the first two modes of displacement $\phi_{I}(z)$ and horizontal velocity $\left(U_{i}(z)\right)$, where $U_{i}(z)$ is got from the linear theory as

$U_{i}=c_{i} \frac{\partial \phi_{i}}{\partial z}$

with the displacement modes normalised such that the maximum value is 1 (as required by the non-linear modelling in Sect. 4).

Here it can be seen that the maximum displacement occurs at around $50 \mathrm{~m}$ depth for the first mode, with a corresponding zero crossing of the horizontal velocity at that depth. The phase speeds of the modes are marked in the legend, together with wavelengths for the $15 \mathrm{~min}$ period wave.

\subsection{Comparison with EOFs}

To determine to what extent the linear modes occur in the observed data, a comparison was made with the empirical orthogonal functions (EOFs) of the data. EOFs are well known as a set of basis vectors (orthogonal and normalised) that explain the variance in a dataset. Each observed data vector can be expressed as a weighted sum of these EOFs.

Here the EOFs are applied to sets of vertical profiles of temperature (from the thermistor chain) giving vertical EOFs. EOFs can be shown (Preisendorfer, 1988) to be the eigenvectors of the covariance matrix $C$ defined by:

$C i j=\sum_{n=1}^{N} \frac{T(i, n) T(j, n)}{N M}$ 
temperature

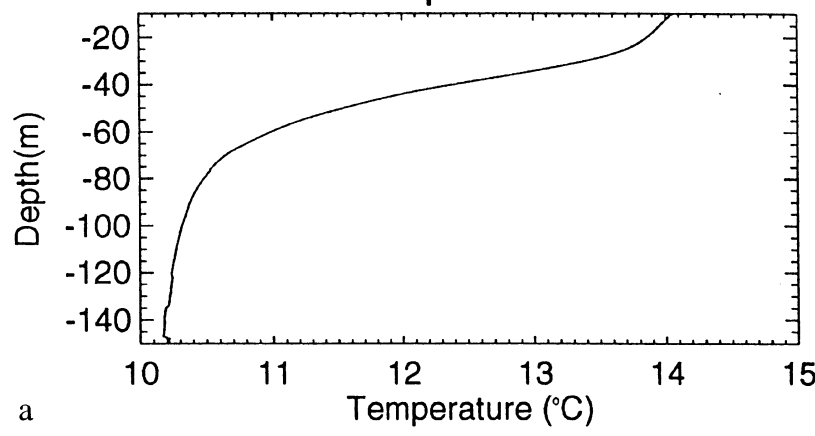

Salinity

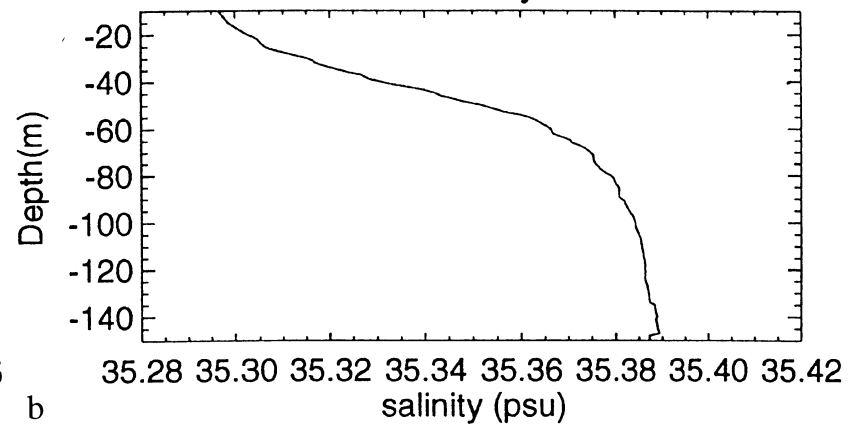

Potential Density
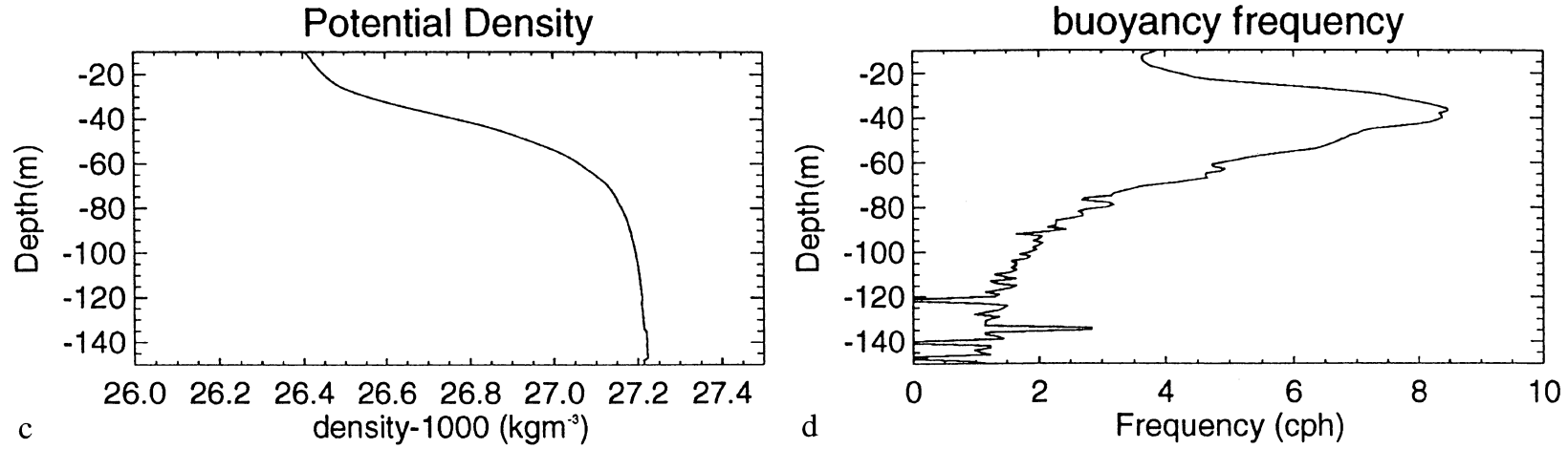

Fig. 10a-d. Mean profiles from 12-14 August, 1996 from SESAME data. a Temperature in ${ }^{\circ} \mathrm{C}, \mathbf{b}$ salinity in psu, $\mathbf{c}$ potential density in kgm ${ }^{-3}$ and d buoyancy frequency $\mathrm{N}$ defined by Eq. 2
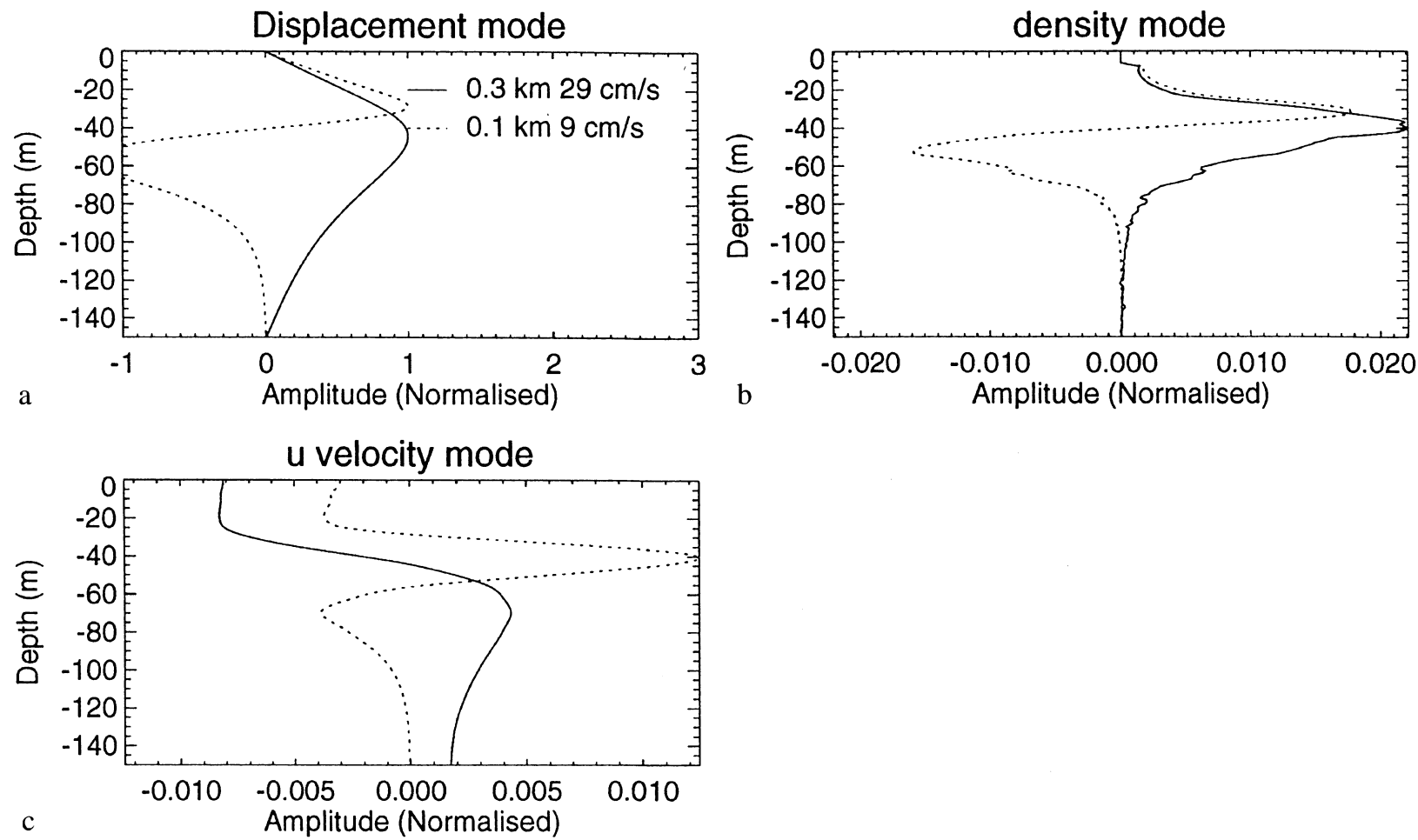

Fig. 11a-c. Linear internal wave modes for the profiles of Fig. 9 and a period of 15 minutes. a Modes of displacement, normalised to a maximum of unity $\mathbf{b}$ modes of density perturbation $\Theta$ and $\mathbf{c}$ modes of $u$ (east-west) velocity. Also indicated are the phase speeds in $\mathrm{cm} \mathrm{s}^{-1}$ and wavelengths in $\mathrm{km}$

where $T(i, n)$ is the temperature at the $i$ th depth point and for the $n$th profile, $N$ is the total number of profiles, and $M$ the number of vertical points.
Hence the EOFs $e_{i}$ are solutions to

$C e_{i}=\lambda_{i} e_{i}$ 
where $\lambda_{i}$ is the eigenvalue that describes the amount of variance due to the eigenvector $e_{i}$.

The eigenvectors were calculated using the IDL (1997) routines TRIRED (to reduce the symmetric matrix to a tri-diagonal one) and TRIQL (to derive the eigenvectors), for each of the set of thermistor chain profiles in surveys 1-4 in turn. Firstly the data was interpolated (linearly) onto a regular depth grid, and then the mean temperature profile subtracted to give the temperature fluctuation values.

Table 2 shows the percentage of variance in each of the first four EOFs, for each of the four surveys in Fig. 4. The dominance of the first EOF is clear for each survey: however the shape of the first EOF changes subtly as shown later. The second EOF contributes to the first survey and has a shape (not shown) similar to the third linear mode.

The dominant first EOF for each survey is compared against the linear modes calculated. (Here, for compatibility, the linear modes were derived from the mean density profiles of each individual survey, giving rise to small variations from the 'mean' modes in Fig. 11. This was done to account for any variation in the phase of

Table 2. Percentage of variance in each of the first four EOFs

\begin{tabular}{lllll}
\hline Survey & EOF 1 & EOF 2 & EOF 3 & EOF 4 \\
\hline 1 & 77 & 16 & 5 & 1 \\
2 & 90 & 6 & 3 & 1 \\
3 & 88 & 8 & 2 & 1 \\
4 & 90 & 7 & 2 & 1 \\
\hline
\end{tabular}

the low frequency internal tide that the internal waves were occurring within.)

The linear modes shown are actually the first 'mode' of density fluctuation $\Theta(z)$, derived from the displacement mode using the linear relation

$\Theta(z)=\phi(z) \frac{\partial \rho}{\partial z}=\phi(z) \frac{N^{2}(z) \rho_{0}}{g}$

where the second equality just follows from the definition of $N(z)$ in Eq. (2). (These modes of density fluctuation should closely compare to those of temperature fluctuation as the importance of salinity to the density profile is minimal here, as discussed already.) To make the observations and models compatible, the dynamical modes were calculated from the mean stratification for each survey and compared to the EOFs for that survey.

Both the linear mode and the EOF are scaled to give a maximum amplitude of unity. The results are shown in Fig. 12 and indicate that in all the surveys the first EOF is similar to the linear mode, with a maximum between 40 and $50 \mathrm{~m}$ depth. The fact that the internal waves are well described by the first EOF/linear mode is the justification for the single-mode numerical modelling in Sect. 4.

These conclusions were confirmed by calculating the EOFs for the ADCP internal $u$ velocities for the same surveys, and comparing with the linear modes of $u$ velocity, as shown in Fig. 13. The linear modes are close to, but not identical to, the EOFs, with a tendency for the EOFs to have a more complex structure in the first two surveys, and to be vertically displaced downwards, relative to the linear mode, in the last two surveys. This
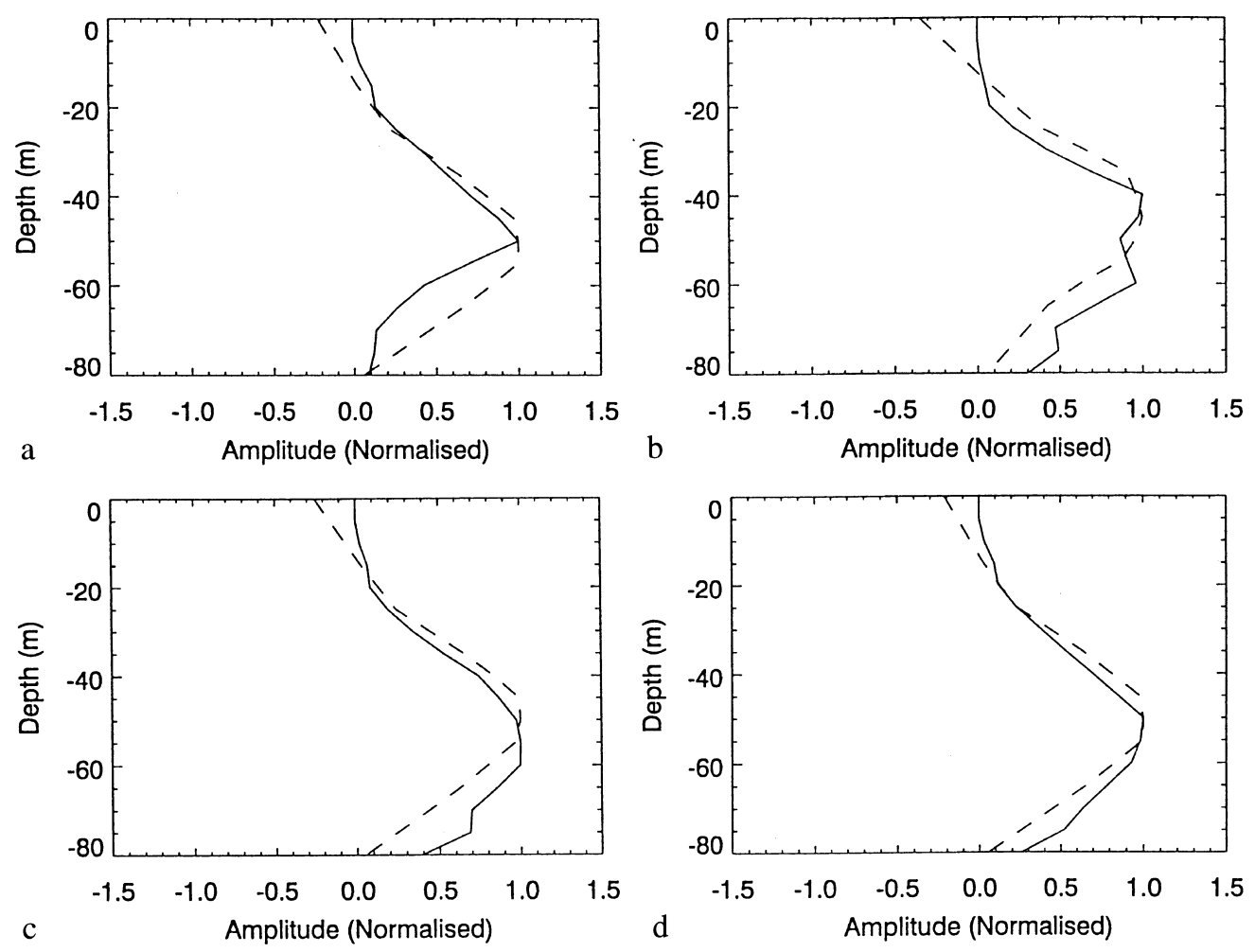

Fig. 12a-d. The first linear mode of temperature fluctuation (solid line) and first EOF (dashed line) for each of the four surveys, $\mathbf{a}-\mathbf{d}$. Both EOF and linear mode are normalised to a maximum of 1 for comparison 
point was also noted in the discussion of the internal currents.

The relative amplitudes of the $u$ velocity EOFs for each survey were similar to the density EOF amplitudes values quoted in Table 3, with survey 1 exhibiting a contribution from higher modes, which can be seen clearly in the $u$ velocity plotted in Fig. 8, showing at least 4 layers (mode 3 ) on the left hand side of the plot. In fact the second EOF for the first survey resembles closely the third linear mode (both in density and $u$ velocity).

\section{Non-linear modelling of the observed bore}

\subsection{Non-linear internal tide theory: solitons and bores}

When the amplitude of the internal tide is large enough (i.e. the ratio $a / H$ is not negligible, where $a$ is amplitude and $H$ characteristic depth) non-linear effects become important which can explain the formation of internal bores and solitons described above. Non linear effects can be modelled either by using fully primitive equation $(P E)$ models, which, however, are computationally expensive and not always easy to interpret, or by using perturbation theory in terms of small parameters, which leads to KdV type equations (Ostrovsky and Stepanyants, 1989: here referred to as OS).

The original formulation of Korteweg and de-Vries (1895) was applicable to surface waves in shallow water, but more recently it has been shown to closely simulate the evolution of internal waves. This KdV theory describes the evolution of the amplitude of a waveform
Table 3. Parameters of the non-linear evolution model

\begin{tabular}{|c|c|c|c|c|c|}
\hline & $\Delta x$ & $\Delta t$ & $\begin{array}{l}\text { Non-linear } \\
\text { coefficient }\end{array}$ & $\begin{array}{l}\text { Dispersive } \\
\text { coefficient }\end{array}$ & $\begin{array}{l}\text { Phase } \\
\text { speed } c_{0}\end{array}$ \\
\hline Dimensional & $30 \mathrm{~m}$ & $9 \mathrm{~s}$ & $\alpha=-0.007$ & $\gamma=207$ & 0.3 \\
\hline Non-dimensional & 0.1 & 0.01 & $\begin{array}{l}A=-0.33(1) \\
A=-0.66(2)\end{array}$ & $G=0.008$ & 1 \\
\hline
\end{tabular}

in a 2 layer or continuously stratified situation. KdV modelling is computationally less expensive than $P E$ calculations, and also leads to some algebraic solutions in simple situations which often agree very well with observations (OS).

The KdV equation has been well studied in recent years, in the context of internal wave generation and propagation. A useful derivation of the equation is given in Pelinovsky et al. (1977). The research prior to 1989 is reviewed in OS, while more recent progress has been made by Pierini (1989), Holloway et al. (1997), Gerkema (1996), Lamb and Yan (1996), and Brandt et al. (1996) amongst many others.

The $\mathrm{KdV}$ equation is derived from the weakly nonlinear equations of motion using a perturbation analysis. The equations of motion are non-dimensionalised in terms of a small non-linearity parameter $\varepsilon(=a / H$ where $a$ is wave amplitude and $H$ depth, or equivalently, $=v_{0} / c$ where $v_{0}$ is the characteristic horizontal velocity and $c$ the characteristic phase speed), and a small dispersion parameter $\delta\left(=(H / L)^{2}\right.$, where $L$ is a horizontal length scale).

Expanding to the first order in these parameters, and re-dimensionalising (Pelinovsky et al., 1977), the resul-
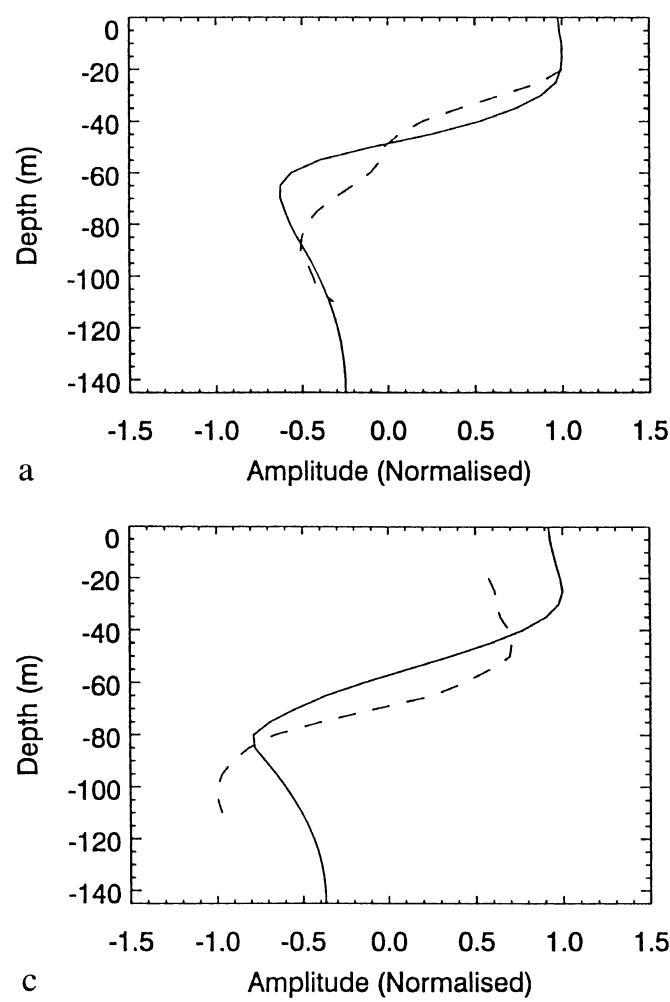
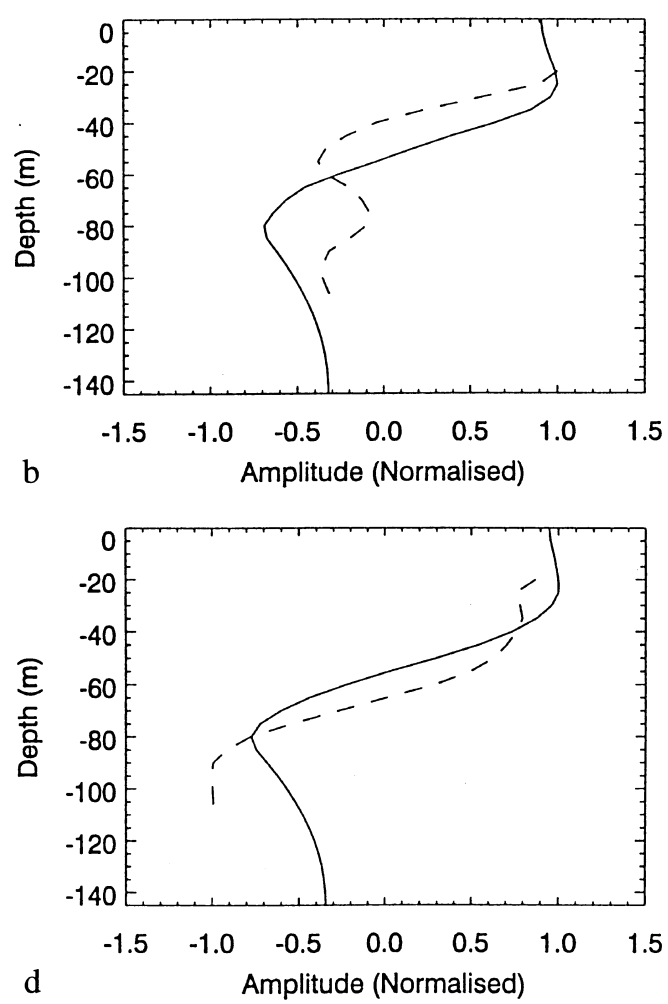

Fig. 13a-d. The first linear mode of $u$ velocity (solid line) and first EOF (dashed line) for each of the four surveys, a-d. Both EOF and linear mode are normalised to a maximum of 1 for comparison 
tant expression for the evolution of the amplitude $\eta(x, t)$ is the basic $\mathrm{KdV}$ equation (OS) for a fluid in two $(x, z)$ dimensions with no rotation

$\eta_{t}+c_{0} \eta_{x}+\alpha \eta \eta_{x}+\gamma \eta_{x x x}=0$

Here $\alpha$ and $\gamma$ are constants dependent on the mean stratification and current regime, $c_{0}$ is the linear phase speed, and subscripts denote differentiation. Here $\alpha$ is the coefficient of the non-linear term and $\gamma$ that of the dispersive term.

The displacement field $d(x, z, t)$ can then be expressed in its simplest form as

$d(x, z, t)=\eta(x, t) \phi(z)$

where the linear mode $\phi(z)$ is scaled to have a maximum of 1 . For a continuous stratification (modal) case with no current shear the coefficients are defined by (Pelinovsky et al., 1977):

$$
\begin{aligned}
& \alpha=\frac{3}{2} c_{0} \frac{\int_{-h}^{0} \phi_{z}^{3} \mathrm{~d} z}{\int_{-h}^{0} \phi_{z}^{2} \mathrm{~d} z} \\
& \gamma=\frac{1}{2} c_{0} \frac{\int_{-h}^{0} \phi^{2} \mathrm{~d} z}{\int_{-h}^{0} \phi_{z}^{2} \mathrm{~d} z}
\end{aligned}
$$

\subsection{The KdV modal model}

To simulate the observed internal bore evolution, a finite difference $\mathrm{KdV}$ model was used, incorporating continuous stratification. The continuous stratification (modal) method was used as the thermocline width $(\sim 60 \mathrm{~m})$ was observed to be significant compared to the water depth of $\sim 150 \mathrm{~m}$.

The linear normal internal wave modes were calculated as in Sect. 3.1, with the water depth fixed at $150 \mathrm{~m}$ (calculations showed that the small water depth variation did not significantly alter the $\mathrm{KdV}$ coefficients, and so a constant depth could be assumed). As discussed already for the shelf environment considered here, the majority of observations from SES and SESAME have indicated a dominance by mode 1 waves, and so this mode is used in the modelling.

The KdV Eq. (8) was non-dimensionalised following Pelinovsky et al. (1977) so that

$$
\begin{aligned}
& X=x / L, \quad Z=z / H, \quad E=\eta / \eta_{0}, \quad T=c t / L, \\
& A=\frac{H \alpha \varepsilon}{c_{0}}, \quad G=\frac{\gamma \delta}{c_{0} H^{2}}, \quad u=\frac{c_{0}}{c}
\end{aligned}
$$

Here $L$ and $H$ are the characteristic horizontal and vertical scales of the motion, $c$ is the characteristic phase speed, and $\eta_{0}$ is the characteristic amplitude. With this the non-dimensional equation is

$E_{T}+u E_{x}+u A E E_{x}+u G E_{x x x}=0$

where $A$ and $G$ are the non-dimensional coefficients of non-linearity and dispersion.

Equation 12 was solved by finite difference using a centred-scheme based on that of Zabusky and Kruskal
(1965), with cyclic boundary conditions well away from the disturbance. (In fact a Gaussian decay to zero is applied to the initial data outside the region of interest.) Here the $x$ coordinate is transformed to one moving with the linear phase speed of $0.29 \mathrm{~m} / \mathrm{s}$, so that the scheme is given by

$$
\begin{aligned}
\frac{E_{i}^{j+1}-E_{i}^{j-1}}{2 \Delta t}= & -A\left(\frac{E_{i+1}^{j}+E_{i}^{j}+E_{i-1}^{j}}{3}\right)\left(\frac{E_{i+1}^{j}-E_{i-1}^{j}}{2 \Delta x}\right) \\
& -G\left(\frac{E_{i+2}^{j}-2 E_{i+1}^{j}+2 E_{i-1}^{j}-E_{i-2}^{j}}{2 \Delta x^{3}}\right)
\end{aligned}
$$

where $I$ and $j$ are time and space indices respectively and $E$ is the non-dimensional displacement at discrete intervals of $\Delta x$ and $\Delta t$ in space and time. Here a mean value of $E$ over 3 points is used to smooth the non-linear term (following Zabusky and Kruskal, 1965).

\section{Experiment 1}

For the bore feature being modelled here, the horizontal length scale $L$ was chosen as the width of one side of the double bore $\sim 300 \mathrm{~m}$, and the vertical scale $H$ was the depth of the maximum of the first linear mode, $50 \mathrm{~m}$ here. Analysis of the variation in depth level of the $11.5^{\circ} \mathrm{C}$ isotherm (the isotherm occurring at $50 \mathrm{~m}$, the depth of the maximum of the first linear mode, and therefore the one described by the term $\eta$ in Eq. 11) indicated that it varied between $35 \mathrm{~m}$ at the right edge of the bore to $63 \mathrm{~m}$ at its deepest (from Fig. 5), about the mean level of $50 \mathrm{~m}$ (from Fig. 10). This implication that the initial bore had approximately equal amplitude about the mean level was used to derive the displacement curve as shown in Fig. 14a. For the non-dimensional model, he displacement curve was normalised by amplitude (half peak-trough) of $\sim 14 \mathrm{~m}$. Consequently the initial amplitude $\eta_{0}$ of the bore was calculated to be $14 \mathrm{~m}$, the non-linearity parameter was $\varepsilon=\left(\eta_{0} / H\right) \sim 0.28$ and the dispersive parameter was $\delta=(H / L)^{2}=0.03$.

\section{Experiment 2}

Another experiment was run to investigate the effect of assuming that the initial waveform was an overall drop in the thermocline level, rather than the oscillation round the zero level shown in Fig. 14a. The displacement curve derived using this method is shown in Fig. 15a, which was used for the second evolution run. The initial maximum amplitude of displacement was then $28 \mathrm{~m}$. In this case the non-linearity parameter $\varepsilon=\left(\eta_{0} / H\right) \sim 0.56$ (in fact, rather large for a first order approximation in $\varepsilon$ ).

Table 3 lists the dimensional and non-dimensional coefficients and grid spacing used in the model for both experiments. Here $\Delta x$ is the horizontal grid spacing, $\Delta t$ is the time step. Runs were also performed with finer time and space steps which showed that the solution had converged for the grid spacing in Table 3. 

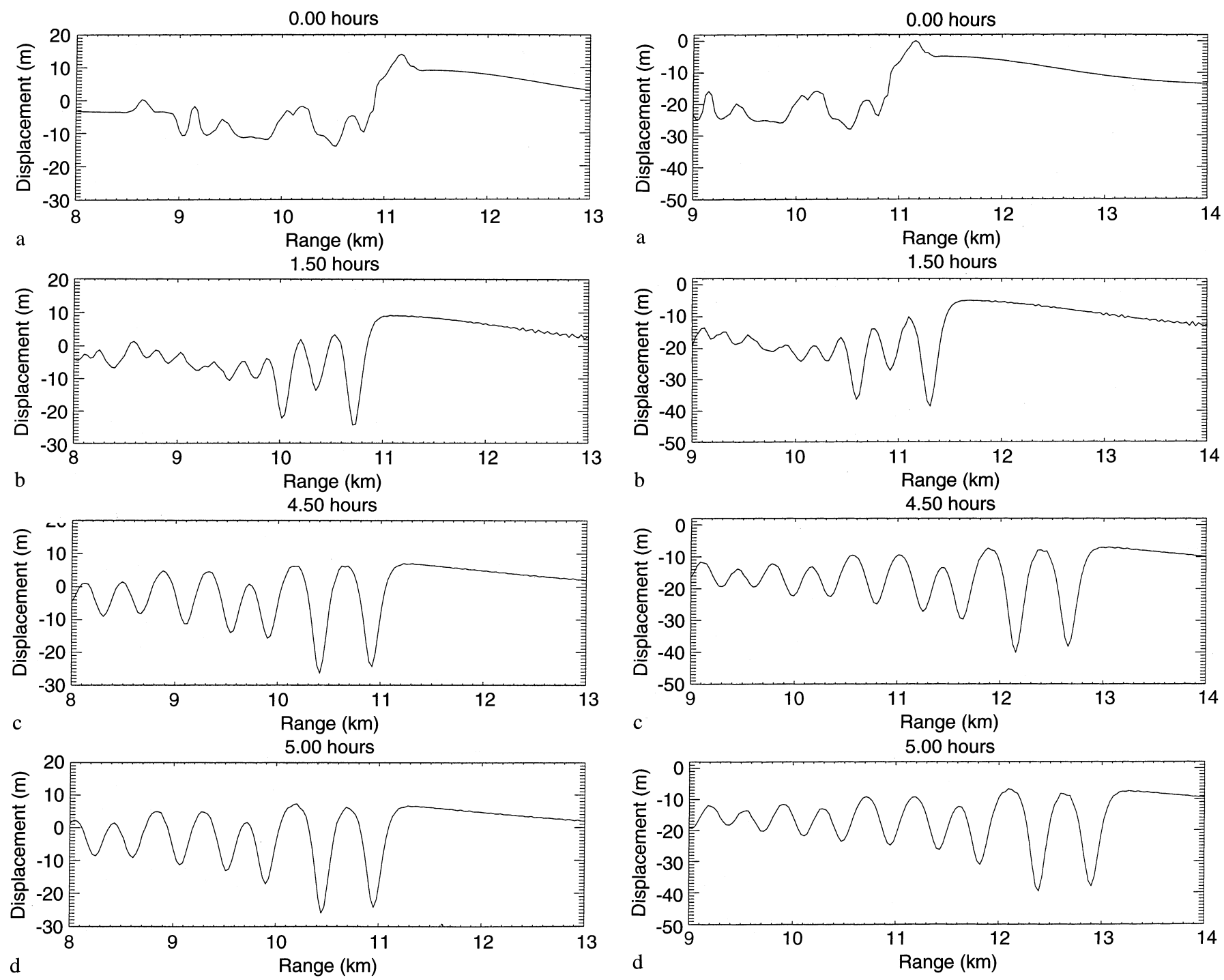

Fig. 14a-d. KdV model results for experiment 1, showing the displacement $\eta$. a Initial waveform, from the first survey; b model run after $1.5 \mathrm{~h}$; c after $4.5 \mathrm{~h}$, and $\mathbf{d}$ after $5 \mathrm{~h}$. Range axis is $\left(x-c_{0} t\right)$ with an arbitrary origin

\subsection{Results}

To investigate the observed evolution of the bore, the initial waveforms (Figs. 14a, 15a) were evolved forward using the KdV model. Figures 4 and 5 shows the model evolved displacement at four time steps during the evolution of experiments 1 and 2 respectively. These time steps (occurring at $0,1.5,4.5$ and $5 \mathrm{~h}$ respectively) were chosen to coincide with the time spacing between the observations of the bore feature in Fig. 4. The range axis is the $\left(x-c_{0} t\right)$ co-ordinate, moving with the linear phase speed, so that differences in the position of waves between the plots is due to non-linear corrections to the phase speed. All amplitudes discussed later are peak-trough.

\section{Experiment 1}

After $1.5 \mathrm{~h}$ (Fig. 14b: corresponding to the second survey of the observations) the leading (right hand)

Fig. 15a-d. KdV model results for experiment 2, showing the displacement $\eta$. a Initial waveform, from the first survey; b model run after $1.5 \mathrm{~h}$; $\mathbf{c}$ after $4.5 \mathrm{~h}$, and $\mathbf{d}$ after $5 \mathrm{~h}$. Range axis is $\left(x-c_{0} t\right)$ with an arbitrary origin

edge has steepened into a large amplitude $(33 \mathrm{~m})$ internal wave, followed by a weaker undulation then another large amplitude $(25 \mathrm{~m})$ wave. This pattern is very similar to the observations (Fig. 5b), and the interwave separations of 300-400 m compares well with the observed separations (Fig. 5b). After 4.5 and $5 \mathrm{~h}$ (comparable to surveys 3 and 4 of the observations) two large amplitude ( 30 and $32 \mathrm{~m}$ ) leading waves have developed followed by a train of 10-20 m waves. The amplitudes and inter-wave separations once again compare well with the observations, for the first two waves, but the following two waves are somewhat less than observed (see Table 4a).

In this case the non-linear correction to phase speed in fact is quite small, and it is difficult to define any real change in position of the bore edge from Fig. 14a to Fig. $14 \mathrm{~d}$, over $5 \mathrm{~h}$, implying a negligible increase in phase speed. This can be contrasted with the experiment 2 results later. 
Table 4a. Comparison of observed (Table 1) and modelled amplitudes of the leading waves in the bore. All amplitudes peak-trough, for each side of the wave, largest first

\begin{tabular}{lll}
\hline Survey & $\begin{array}{l}\text { Observed } \\
\text { amplitude }(\mathrm{m})\end{array}$ & $\begin{array}{l}\text { Modelled amplitude } \\
(\mathrm{m}) \text { experiment } 1\end{array}$ \\
\hline 2 & & \\
Wave 1 & $37 / 23$ & $33 / 27$ \\
Wave 2 & $13 / 13$ & $16 / 16$ \\
Wave 3 & $20 / 20$ & $24 / 18$ \\
3 & & \\
Wave 1 & $30 / 25$ & $31 / 31$ \\
Wave 2 & $26 / 17$ & $34 / 34$ \\
Wave 3 & $35 / 20$ & $22 / 16$ \\
Wave 4 & $37 / 30$ & $19 / 15$ \\
4 & & \\
Wave 1 & $32 / 23$ & $30 / 30$ \\
Wave 2 & $28 / 23$ & $34 / 34$ \\
Wave 3 & $27 / 25$ & $24 / 19$ \\
Wave 4 & $22 / 20$ & $18 / 15$ \\
\hline
\end{tabular}

Table 4b. Comparison of observed (Table 1) and modelled phase speeds of the leading wave in the bore. The observed value for Sect. 3-4 is only approximate (see Sect. 2.2)

\begin{tabular}{lcll}
\hline Survey & $\begin{array}{l}\text { Observed phase } \\
\text { speed } \\
\mathrm{cm} \mathrm{s}^{-1}\end{array}$ & $\begin{array}{l}\text { Experiment 1 } \\
\text { Phase speed } \\
\mathrm{cm} \mathrm{s}^{-1}\end{array}$ & $\begin{array}{l}\text { Experiment 2 } \\
\text { Phase speed } \\
\mathrm{cm} \mathrm{s}^{-1}\end{array}$ \\
\hline $1-2$ & 26 & 27 & 38 \\
$2-3$ & 35 & 31 & 41 \\
$3-4$ & $\sim 28$ & 33 & 40 \\
$1-4$ (total) & 32 & 30 & 40 \\
\hline
\end{tabular}

\section{Experiment 2}

The experiment 2 results in Fig. 15, for an initial wave of depression, have the same waveforms as those in experiment 1 . However, the difference between the two experiments is in the significant progression of the leading waves due to non-linear phase speed. The leading wave has moved an extra $2 \mathrm{~km}$ in the $5 \mathrm{~h}$ duration, implying that the non-linear correction is $+0.11 \mathrm{~m} \mathrm{~s}^{-1}$, giving a total phase speed for the leading wave of $0.4 \mathrm{~m} \mathrm{~s}^{-1}$.

Table $4 \mathrm{~b}$ details the phase speeds from the two experiments for the lead wave. Here the modelled phase speed is the sum of the linear speed $0.29 \mathrm{~m} / \mathrm{s}$ and the non-linear correction derived from Figs. 14 and 15. The results from Table $4 \mathrm{~b}$ indicate that the first experiment is closest to the observations, in terms of the phase speed of the waves, which do not differ significantly from the linear speed. In contrast, the phase speeds in experiment 2 are some $10 \mathrm{~cm} \mathrm{~s}^{-1}$ too large, compared to the observations. In the next section a suggestion of why the wave speeds differ is discussed.

\subsection{Soliton analysis of the internal waves}

To investigate the validity of the first order $\mathrm{KdV}$ equations for these observations, an analysis was done of the large amplitude internal waves in terms of soliton theory. The $\mathrm{KdV}$ soliton is a non-periodic solution to the $\mathrm{KdV}$ equation and is given by

$\eta(x, t)=\eta_{0} \operatorname{sech}^{2}\left(\left(\left(x-x_{c}\right)-c_{1} t\right) / L\right)$

Here $\eta_{0}$ is the maximum displacement, $x_{c}$ is the soliton central position, and $L$ (the soliton half width) and $c_{1}$ (the soliton phase speed) are given by

$a \quad L^{2}=\frac{12 \gamma}{\eta_{0} \alpha} \quad b \quad c_{1}=c_{0}\left(1+\frac{\eta_{0} \alpha}{3 c_{0}}\right)$

where $c_{0}, \alpha$ and $\gamma$ are the linear phase speed, and parameters of non-linearity and dispersion defined in Sect. 4.1.

These equations imply that the soliton half width $L$ and maximum amplitude $\eta_{0}$ are related by an inverse square law. Similarly the phase speed increase is linearly dependent on amplitude, and in fact will increase with increasing amplitude in this environment (as here the $\eta_{0}$ are negative (waves of depression), and the coefficients $\alpha$ and $\gamma$ are negative and positive respectively, from Table 3).

Predictions of the width $L$ of $\mathrm{KdV}$ solitons from the amplitudes of the observed internal waves (from surveys 3 and 4) are compared with the observed widths $W$. Here $W$ was obtained from Fig. 5 by searching for the point where the amplitude of the waves reduces to 0.42 times the maximum amplitude (the half width: this follows from the definition of the soliton half width in Eq. 14). The results are shown in Table 5. The uncertainties in Table 5 are due to the different values from measurements in surveys 3 and 4 , and for the half widths on either side of the wave. It is clear that the measurements indicate asymmetry for the waves, as visible in Fig. 5.

The measurement of uncertainty is important in this context as can be seen from Fig. 16. Here the KdV amplitude-half width relationship is plotted for the coefficients $\alpha$ and $\gamma$ of Table 3. It can be seen that the amplitude varies from $8 \mathrm{~m}$ to $35 \mathrm{~m}$ as half width reduces from 200 to $100 \mathrm{~m}$. In other words, the estimate of amplitude from half width is critically sensitive to the half width measurement, due to the inverse square law in Eq. (15). The lower bound estimates of the widths $W$ in Table 5 are consistent with the $\mathrm{KdV}$ predictions, but the upper bounds are not. Clearly the uncertainty in Table 5 cannot resolve the question of whether the internal waves are $\mathrm{KdV}$ solitons.
Table 5. Observed and predicted soliton half-widths

\begin{tabular}{lllll}
\hline & Wave 1 & Wave 2 & Wave 3 & Wave 4 \\
\hline Amplitude (m) & $-28 \pm 5$ & $-23 \pm 5$ & $-27 \pm 8$ & $-27 \pm 9$ \\
Width W (m) & $150 \pm 50$ & $140 \pm 30$ & $150 \pm 40$ & $140 \pm 20$ \\
Predicted width L (m) & $104-124$ & $113-140$ & $101-137$ & $99-140$ \\
Predicted phase speed $c_{1}\left(\mathrm{~cm} \mathrm{~s}^{-1}\right)$ & $35-38$ & $34-36$ & $34-38$ & $34-38$ \\
\hline
\end{tabular}



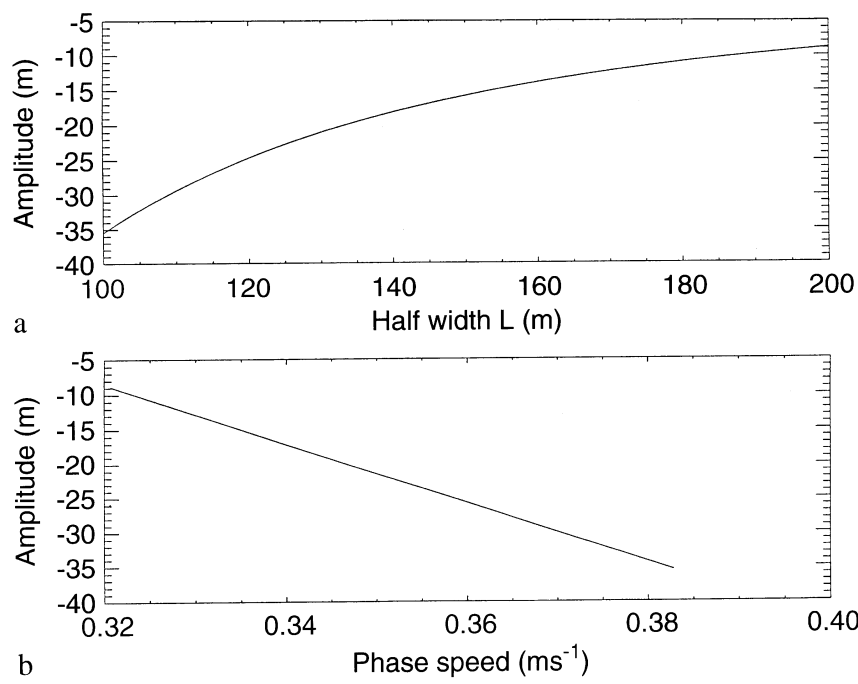

Fig. 16a, b. KdV predictions of a soliton half width $L$ and $\mathbf{b}$ phase speed $c$ for waves with given amplitudes, for the stratification and modes shown in Figs. 10 and 11

A brief investigation was done of the predictions of 2nd order non-linear theory. Following Gear and Grimshaw (1983: GG), an equivalent two layer model was analysed. Here, the layer interface was chosen as the depth of the maximum of the first mode, $50 \mathrm{~m}$ from Fig. 11.

GG gave expressions for the second order corrections to the $\mathrm{KdV}$ soliton theory. The dimensional forms of these expressions are

$$
\begin{aligned}
& \lambda=L(1-\kappa) \\
& c=c_{1}+c_{2}
\end{aligned}
$$

where $\lambda$ and $c$ are the corrected half width and phase speed, $L$ and $c_{1}$ are the first order half width and phase speed, and $\kappa$ and $c_{2}$ are the second order adjustments. Further the shape of the wave is altered from that given by Eq. (14) by a factor

$1+\eta_{0} \gamma \tanh ^{2}\left(\frac{\left(x-x_{c}\right)-c t}{\lambda}\right)$

where the parameter $\gamma$ describes the flattening (or sharpening) of the peak of the wave relative to the first order sech shape.

GG illustrated the adjustments $\kappa, c_{2}$ and $\gamma$ for two layer fluids with different relative layer depths. With a top layer depth of $50 \mathrm{~m}$ and a lower layer depth of $100 \mathrm{~m}(d / h=0.33$ in GG terminology $)$, the calculations of GG indicate that the values of $\kappa$ and $c_{2}$ are -0.56 and $-0.1 c_{0}$ respectively for a wave of amplitude $-28 \mathrm{~m}$ in water depth $150 \mathrm{~m}(a / h \sim 0.2$ in GG terminology $)$, and $\gamma=-0.013$.

This implies that the second order half width is 1.56 times the first order estimate, and the phase speed is reduced from the $\mathrm{KdV}$ prediction by 0.1 times the linear speed, and the wave is very slightly flattened in shape. For the example of a wave of amplitude $-28 \mathrm{~m}$ and first order half width $113 \mathrm{~m}$, this would imply a corrected width $L \sim 176 \mathrm{~m}$, and a phase speed reduction of just
$3 \mathrm{~cm} \mathrm{~s}^{-1}$ from $36 \mathrm{~cm} \mathrm{~s}^{-1}$ to $33 \mathrm{~cm} \mathrm{~s}^{-1}$. It follows that the measurements of half width $W$ in Table 5, lie somewhere within the predictions of first $(\mathrm{KdV})$ and second $(\mathrm{GG})$ order non-linear theory.

It is interesting to compare the expected soliton phase speeds with the speeds from the evolution model. From the previous paragraph a $\mathrm{KdV}$ soliton of $-28 \mathrm{~m}$ amplitude has a phase speed of $36 \mathrm{~cm} \mathrm{~s}^{-1}$. Experiment 1 of the evolution model yielded speeds of $33 \mathrm{~cm} \mathrm{~s}^{-1}$ (Table $4 \mathrm{~b}$, between surveys $3-4$ ), for a similar amplitude lead wave, and experiment 2 yielded $40 \mathrm{~cm} \mathrm{~s}^{-1}$. It seems unusual that the $\mathrm{KdV}$ soliton phase speed does not match the speed of the waves in the $\mathrm{KdV}$ evolution model, for similar peak-trough wave amplitudes. However, if one interprets the amplitudes of the waves as the displacement from the zero level, giving amplitudes of $-24 \mathrm{~m}$ and $-38 \mathrm{~m}$ for experiments 1 and 2 respectively (Figs. 14, 15), and corresponding KdV soliton phase speeds of $34.5 \mathrm{~cm} \mathrm{~s}^{-1}$ and $38 \mathrm{~cm} \mathrm{~s}^{-1}$, the measurements are far more consistent. This offers an explanation for the generally faster speeds of experiment 2, which compare badly with the observations when measuring from survey 1 to survey 4: the initial wave is not a wave of depression but an oscillation about the mean level. Clearly it is important to correctly interpret the mean (zero) level of displacement when modelling internal wave evolution.

\section{Discussion: comparison with ERS SAR imagery}

In Sect. 2.6 it was mentioned that the propagation direction of the waves could only be estimated from the internal currents in the ADCP data, which are poorly sampled. The data appeared to show that the internal bore in the first survey was moving due east, but no indication could be given of the directions of the later high frequency internal waves.

Some indication of the likely directions in this region can also be obtained from SAR imagery obtained during the same experiment but some 8 days later. Figure 17 shows a close up of the SESAME region from an ERS-2 SAR image at 1136 UTC on the 21st August, 1996. The image is interesting for a number of reasons:

1. The presence of a long wavefront (hereafter termed 'B') parallel to the shelf edge and some $10 \mathrm{~km}$ onshelf, with following waves. These are possibly internal waves associated with the shelf-edge generated internal tide. The leading bright (high backscatter) edge and following dark edge suggests internal waves of depression, similar to the observations here.

2. A dark band, about $10 \mathrm{~km}$ wide, ahead of the wavefront. This may be due to the modulation of surface films by the long wavelength internal tide reported by Ermakov et al. (1998).

3. Large amplitude features over the continental slope, between the $160 \mathrm{~m}$ and $600 \mathrm{~m}$ contours, namely a well-dispersed soliton packet to the south (between 


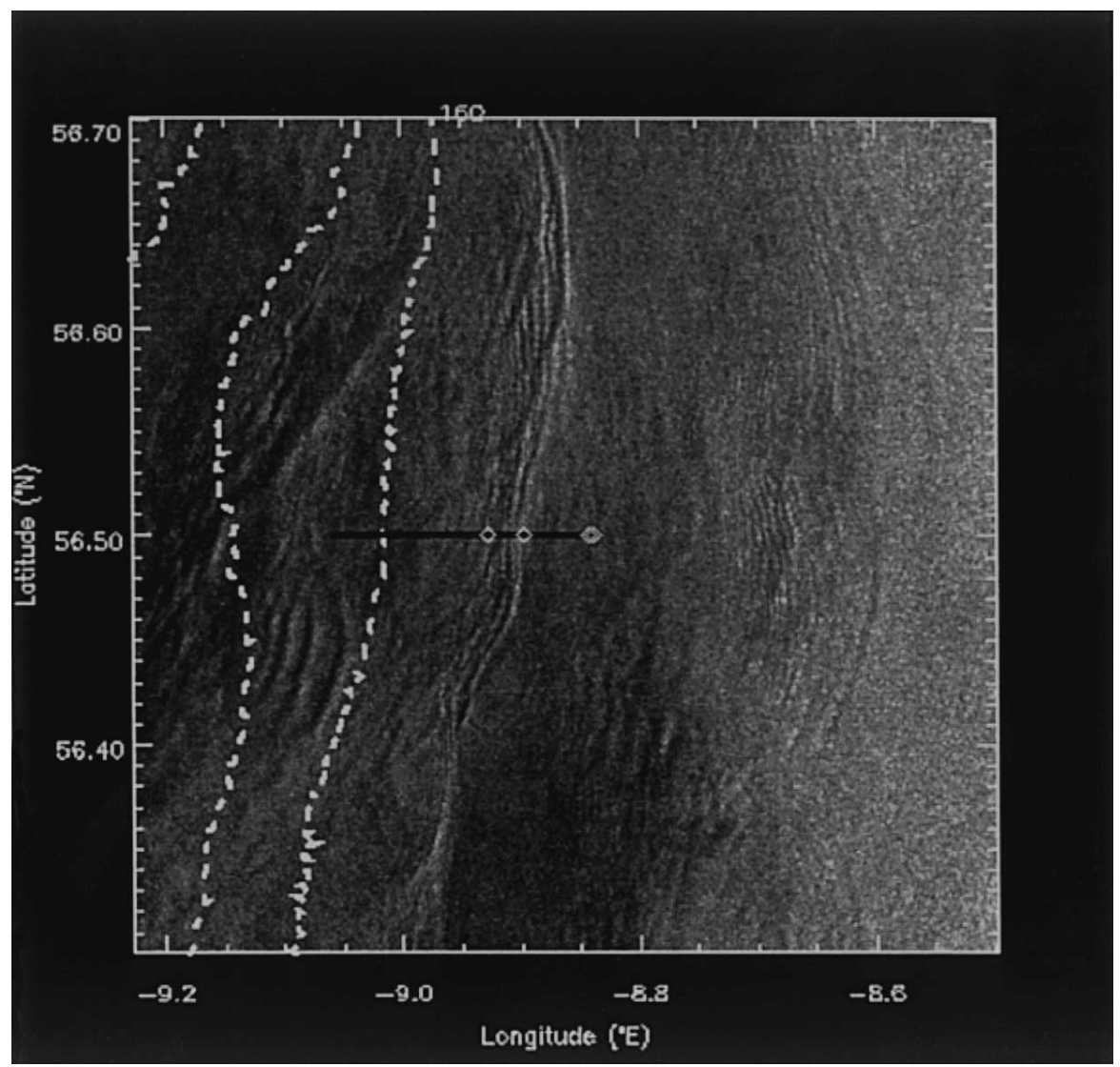

Fig. 17. ERS-2 SAR image from 1136 UTC, 21 August, 1996, showing the SESAME region. Bathymetry contours are marked as white dashes, for $160 \mathrm{~m}, 600 \mathrm{~m}$ and $1000 \mathrm{~m}$, from right to left. Also marked is the survey track from Fig. 3, with diamonds marking the positions of the leading edge of the internal bore feature during the four surveys (surveys 3 and 4 closely overlapping)

56.4 and $56.5 \mathrm{~N}$ ) of the survey track, and a developing bore further north (between 56.5 and 56.6). These waves are apparently propagating from the deep towards the shelf edge.

4. Weaker internal wave signatures east of the thick dark band (between 8.7 and $8.6 \mathrm{~W}$ ). These may be signatures of the previous internal tide.

The features identified on this image will be discussed in more detail in a later paper. Here we just want to note that at the position of the bore observations made by thermistor chain in this paper (marked as diamonds on Fig. 17), the propagation direction of the main wavefront ' $\mathrm{B}$ ' is close to due east, but with some localised variations. The structure of this long-crested internal wave-packet in the latitudinal direction has interesting finer structure, including variations in the number and direction of the following waves.

It is possible that the observations of Sect. 2 show signatures of an earlier version of this long wave-packet (similarities include the position on the shelf, as shown in Fig. 17., and the fact that the following waves are not well separated, suggesting proximity to the generation site, possibly the shelf edge). However further quantitative comparison of the SAR and thermistor chain observations will not be made, due to the long separation in time ( $\sim 16$ tidal cycles, and so at opposite ends of the spring-neap cycle), and the possible variation in stratification which could affect the wave phase speeds.

\section{Summary and conclusions}

During the SESAME trial at the Malin shelf edge in the summer of 1996 a large number of repeated observations of internal tide formation at the shelf break were made. Thermistor chain records showed the thermocline fluctuations to high resolution, while ADCP records indicated the current structure at a coarser resolution.

This paper has analysed in detail one example of the formation of high frequency internal waves from an initial internal bore that was generated further offshelf. (The generation process will be discussed separately in a future paper.) Four tows were made across the feature as it evolved and propagated onshelf at a first mode phase speed of $\sim 30 \mathrm{~cm} \mathrm{~s}^{-1}$ across the shelf in water depths of around $150 \mathrm{~m}$. The data surveys were converted to approximate 'snapshots' or range series by removing the Doppler shift due to the speed across ground of the waves, assumed to be $30 \mathrm{~cm} \mathrm{~s}^{-1}$ everywhere.

Initially the internal bore had a peak-trough amplitude of $28 \mathrm{~m}$ and was double-sided, with a total extent of $\sim 600 \mathrm{~m}$. Undulations then developed within this 'well' shaped bore after $1.5 \mathrm{~h}$, and $3 \mathrm{~h}$ later four large internal waves had developed with separations of about $500 \mathrm{~m}$, half widths around 100-200 m, and amplitudes up to $30 \mathrm{~m}$.

Analysis of the currents indicated that initially the bore was associated with a strong offshelf flow in the top layer, opposing the onshelf tidal flow at that time. As the 
tide weakened this top layer flow became dominant. Later the internal waves were associated with current structures but were not well resolved by the ADCP. The internal currents associated with the initial internal bore appeared to indicate a cross-shelf, eastward propagation direction, a point suggested by analysis of the internal tide in a later SAR image of the region.

EOFs were calculated for each of the four surveys for both the temperature and the $u$-velocity fluctuations, and compared to the linear dynamical modes for the environment. This comparison revealed that the surveys were dominated by the first linear mode, with a smaller third mode contribution.

Predictive modelling was done of the feature evolution to assess the extent it could be described by $\mathrm{KdV}$ theory. A finite difference $\mathrm{KdV}$ model was run for an initial condition set equal to the first survey of the feature. The results gave a good prediction of the length scales, phase speeds and amplitudes of the waves over the $5 \mathrm{~h}$ evolution period. It was further found that the modelling of phase speeds was critically dependent on the definition of the mean level of the initial bore.

An interesting feature of the observations is that the wave packet is not a rank ordered packet, as would be expected to evolve from an idealised initial waveform, (such as a sine wave or Gaussian curve) following the well-known $\mathrm{KdV}$ properties (OS). However, the fact that the model and observations agree closely in the shape of the evolved waveforms indicates that it is the initial condition that gives rise to the disordered packet, and not an inadequacy of the KdV theory. Computer animation of the model results confirm that the finestructure in the initial wave gives rise to the evolved internal waves, rather than an ordered disintegration of the long wave in the classic undular bore manner. (Of course, it is the combination of the structure of the initial waveform, and the $\mathrm{KdV}$ properties, which gives rise to the observed evolution.)

The internal waves were analysed in terms of first order $\mathrm{KdV}$ and second order extended $\mathrm{KdV}$ soliton theory. Due to uncertainties in the measurements, exact conclusions could not be made, but the waves appear to lie between the predictions of the first and second order theory. Predictions of the evolution of the initial waveform in terms of the extended theory are currently being studied by the authors.

Acknowledgements The authors would like to thank the SES community for making available data concurrent with SESAME under the CAROS agreement, together with Shanti Ramsey and Kate Kelly of DERA for analysis of SESAME data. Thanks also to Dr Toby Sherwin and Jeff Jackson for providing the linear modal analysis code.

Topical Editor D.J. Webb thanks A. New and P. Holloway for their help in evaluating this paper.

\section{References}

Alpers, W., Theory of radar imaging of internal waves, Nature, 314, 245-247, 1985.

Baines, P. G., On internal tide generation models, Deep Sea Res., 29, 307-338, 1982.
Brandt, P., W. Alpers, and J. O. Backhaus, Study of the generation and propagation of internal waves in the Strait of Gibraltar using a numerical model and radar images from the European ERS-1 satellite. J. Geophys. Res., 101 (C6), 14 237-14 252, 1996.

Ermakov S. A., J. C. B. Da Silva, and I. S. Robinson, Role of surface films in ERS SAR signatures of internal waves on the shelf 2. Internal tidal waves, J. Geo. Res., 103, C4, 8033-8043, 1998.

Gargett, A. E., Generation of internal waves in the Strait of Georgia, British Columbia, Deep Sea Res., 1976, Vol. 23 $17-32$.

Gasparovic, R. F., J. R. Apel, and E. S. Kasischke, An overview of the SAR internal wave signature experiment, J. Geophys. Res., 93, c10, 12 304-12 316, 1988.

Gear, J. A., and R. Grimshaw, A second order theory for solitary waves in shallow water, Phys. Fluids, 26 (1), 14-29, 1983.

Gerkema, T., A unified model for the generation and fission of internal tides in a rotating ocean, J. Mar. Res., 54, 421-450, 1996.

Henyey, F. S., and A. Hoering, Energetics of borelike internal waves, J. Geophys. Res., 102, 3323-3330, 1997.

Holloway, P. E., E. N. Pelinovsky, T. G. Talipova, and B. Barnes, A non-linear model of internal tide transformation on the Australian North-West Shelf, J. Phys. Oceanogr., 27 (6), 871896, 1997.

Huthnance, J. M., Internal tides and waves near the continental shelf edge, Geophys. Astrophys. Fluid Dyn., 48, 81-106, 1989.

IDL, Interactive data language reference guide, Research Systems, 2995 Wilderness Place, Boulder, Colorado, USA, 1997.

Korteweg, D. J., and G. de Vries, On the change of form of long waves advancing in a rectangular channel, Philos. Mag., 39, $422,1895$.

Lamb, K. G., Numerical experiments of internal wave generation by strong tidal flow across a finite amplitude bank edge, J. Geophys. Res., 99, C1, 848-864, 1994.

Lamb, K. G., and L. Yan, The evolution of internal wave undular bores: comparisons of a fully non-linear numerical model with weakly non-linear theory, J. Phys. Oceanogr, 26, 2712-2734, 1996.

Lee, C. Y., and R. C. Beardsley, The generation of long nonlinear internal waves in a weakly stratified shear flow, J. Geophys. Res., 79 (3), 453-462, 1974.

McCartney, B., and J. M. Huthnance, Shelf edge study - RRS Challenger Cruise 91A and 91B, POL Cruise Rep. 20, 1995.

Maxworthy, T., A note on the internal solitary waves produced by tidal flow over 3 dimensional ridge, J. Geophys. Res., 84, C1, 338-346, 1979.

New, A. L., and R. D. Pingree, Large amplitude internal soliton packets in the central Bay of Biscay, Deep Sea Res., 37, 513524, 1990.

Ostrovsky, L. A., and Y. A. Stepanyants, Do internal solitons exist in the ocean, Rev. Geophys., 27, 293-310, 1989.

Pelinovsky, E. N., M. A. Rayevskiy, and S. K. Shavratskiy, The Korteweg-de Vries equation for nonstationary internal waves in an inhomogeneous ocean, Izv Atmos Ocean Physi., 13 (3), 226$228,1977$.

Pierini, S., A model for the Alboran Sea internal solitary waves, J. Phys. Oceanogr., 19, 755-772, 1989.

Pingree, R. D., D. K. Griffiths and G. T. Mardell, The structure of the internal tide at the Celtic Sea shelf break, J. Mar. Bio. Ass. $U K$, 64, 99-113, 1983.

Preisendorfer, R. W., Principal component analysis in meteorology and oceanography, Ed; C B Mobley, Elsevier, New York pp 392, 1988.

Small, J., G. Pavey, Z. Hallock and J. C. Scott, Observations of large amplitude internal waves at the Malin Shelf edge during SESAME 1995, submitted to Cont. Shelf Res., 1998.

UNESCO Algorithms for computation of fundamental properties of sea water, UNESCO Techn. pap. Mar. sci., 44, 1983.

Zabusky, N. J., and M. D. Kruskal, Interaction of solitons in a collisionless plasma and the recurrence of initial states, Phys. Rev. Lett., 15, 250-243, 1965. 